Portland State University

PDXScholar

Fall 12-12-2019

\title{
The Optimized Synthesis of Copper Nanowire for High-quality and Fabrication of Core-Shell Nanowire
}

Suhyun Lee

Portland State University

Follow this and additional works at: https://pdxscholar.library.pdx.edu/open_access_etds

Part of the Materials Science and Engineering Commons Let us know how access to this document benefits you.

\section{Recommended Citation}

Lee, Suhyun, "The Optimized Synthesis of Copper Nanowire for High-quality and Fabrication of Core-Shell Nanowire" (2019). Dissertations and Theses. Paper 5386.

https://doi.org/10.15760/etd.7259

This Thesis is brought to you for free and open access. It has been accepted for inclusion in Dissertations and Theses by an authorized administrator of PDXScholar. Please contact us if we can make this document more accessible: pdxscholar@pdx.edu. 
The Optimized Synthesis of Copper Nanowire for High-quality and Fabrication of

\author{
Core-Shell Nanowire
}

by

Suhyun Lee

A thesis submitted in partial fulfillment of the requirements for the degree of

Master of Science
in
Mechanical Engineering

Thesis Committee:

Sung Yi, Chair

Faryar Etesami

Chien Wern

Portland State University

2019 
(c) 2019 Suhyun Lee 


\begin{abstract}
Flexible electronics are the promising technology for prospective application in foldable phones. Currently, indium tin oxide (ITO) has been widely used for electronic devices including flat-panel display. However, it is brittle and expensive. Metal nanowires are considered as alternative materials. Among various metal nanowires, copper nanowires are attractive because of its high electrical conductivity, better flexibility, and low cost compared with ITO. However, copper nanowires are very prone to oxidize, which causes subsequently degradation of electrical conductivity. Due to this oxidation issue, core-shell structure nanowires, which are formed silver shell having high conductivity and low resistivity on the surfaces of copper nanowires are considered to enhance oxidation resistance. The objective of the present study is to optimize the synthesis of copper nanowires to improve yields changing synthesis and increasing the dimensions of the nanowires. Copper nanowires are synthesized under various conditions, which are different concentrations of hydrazine $\left(\mathrm{N}_{2} H_{4}\right)$, ethylenediamine (EDA), sodium hydroxide $(\mathrm{NaOH})$, and copper precursor, and synthesis temperatures. In addition, a new facile method using an eco-friendly organic compound A is developed to fabricate copper-silver core-shell structure $(\mathrm{Cu}-\mathrm{Ag})$ nanowires.

The highest yield of copper nanowires is obtained with the length of $4-13 \mu \mathrm{m}$ and the diameter of $250-550 \mathrm{~nm}$ with an amount of $15 \mu \mathrm{l}$ of diluted $\mathrm{N}_{2} H_{4}$. The excessive amount of diluted $\mathrm{N}_{2} \mathrm{H}_{4}$ leads to an unbalance in the process and causes formation
\end{abstract}


of copper nanoparticles. The smooth surface of copper nanowires is observed at synthesis temperature of $70^{\circ} \mathrm{C}$. This is because EDA is likely actively performed at 70 ${ }^{\circ} \mathrm{C}$ to protect the surface of copper seeds to prevent the aggregation. The insufficient amount of EDA induces copper seeds, which aid not grow to copper nanowire, and the formation of tapered copper nanowires, while the excessive amount of EDA causes the irregular surface of copper nanowires. High-quality copper nanowires, which have the length of longer than $18 \mu \mathrm{m}$ and the diameter of $25-45 \mathrm{~nm}$, are obtained by controlling the concentration of $\mathrm{NaOH}$ from $14.7 \mathrm{M}$ to $9 \mathrm{M}$. NaOH concentration below $9 \mathrm{M}$ is required the increased amount of EDA to prevent forming copper seeds from being aggregated. When the concentration of copper precursor is increased, copper nanowires become shorter in length and thicker diameter and the aggregation of copper seeds is observed. $\mathrm{Cu}-\mathrm{Ag}$ nanowires are fabricated successfully by a new facile method using eco-friendly organic compound A. The result shows the thickness of silver shell close to $12 \mathrm{~nm}$.

This study indicates various synthesis conditions for copper nanowires to find the optimum condition and shows a new facile method to eco-friendly fabricate $\mathrm{Cu}-\mathrm{Ag}$ nanowires. In addition, this study provides high potential in extensive applications of these nanowires such as flexible and stretchable devices. 


\section{Acknowledgements}

First of all, I would like to express infinite gratitude to my advisor, Professor Sung Yi, who led me to study and gave me awesome opportunity and encouragement to do this research. I would like to appreciate his support during my master. In addition, I would like to thank my other committee members, Associate Professor Faryar Etesami and Associate Professor Chien Wern.

I especially would like to express thank to my love family for their infinite support, encouragement, and belief in me. I love you! 


\section{Table of Contents}

Abstract $\quad$ i

Acknowledgements

iii

List of Tables $\quad$ vi

List of Figures $\quad$ vii

Chapter 1 Introduction 1

1.1 Background .......................... 1

1.2 Literature review . . . . . . . . . . . . . . . . . 4

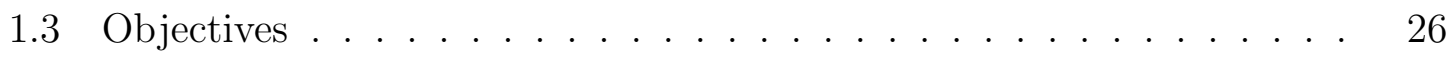

$\begin{array}{lll}\text { Chapter } 2 & \text { Synthesis of Copper Nanowire } & 27\end{array}$

2.1 Materials . . . . . . . . . . . . . . . . 27

2.2 Experimental Procedure . . . . . . . . . . . . . . . 28

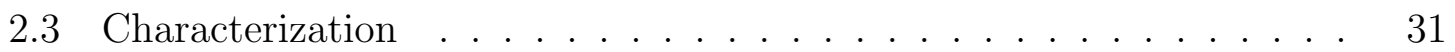

2.4 Results.............................. 33

2.5 Discussion . . . . . . . . . . . . . . . . . . . . . . 49 
Chapter 3 Fabrication of Core-Shell Nanowire

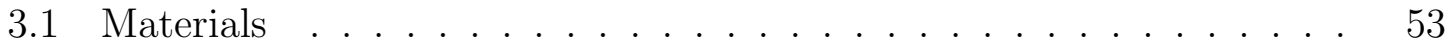

3.2 Experimental Procedure . . . . . . . . . . . . . . . 53

3.3 Results . . . . . . . . . . . . . . . . . . . 54

3.4 Discussion . . . . . . . . . . . . . . . . . 57

$\begin{array}{lll}\text { Chapter } 4 \text { Conclusions } & 58\end{array}$

$\begin{array}{ll}\text { Bibliography } & 61\end{array}$ 


\section{List of Tables}

1.1 Physical properties of potential transparent electrodes (Hsu et al. [2013]; Hu et al. [2011]; Lee et al. [2012]) . . . . . . . . . . . . . . . . . 2

1.2 An overview of copper nanowire synthesis methods . . . . . . . . . . 7

1.3 The effect of synthesis temperature and time on dimensions of copper nanowire with EDA and $\mathrm{N}_{2} H_{4}$ showing higher synthesis temperature resulted in shorter length . . . . . . . . . . . . . . . 99 9

1.4 Various capping and reducing agents reported to be used for synthesis of copper nanowire . . . . . . . . . . . . . . . . . . . . 10

2.1 Experimental conditions of chemicals . . . . . . . . . . . . . . 30

2.2 Experiment conditions of diluted $\mathrm{N}_{2} H_{4} \ldots \ldots . \ldots 33$

2.3 Experiment conditions for the effect of concentration of $\mathrm{NaOH}$. . . . . . 43

3.1 Experimental condition of chemicals . . . . . . . . . . . . 54 


\section{List of Figures}

1.1 An overview of copper nanowire synthesis methods . . . . . . . . . . 6

1.2 SEM image of copper nanowire reported by Rathmell et al. [2010] showing the presence of spherical seed on one end of the nanowires $\ldots \ldots . .9$

1.3 SEM images of copper nanowires synthesized at various temperature: (a) $4{ }^{\circ} \mathrm{C}$, (b) $30{ }^{\circ} \mathrm{C}$, and (c) $80{ }^{\circ} \mathrm{C}$ (Nuryadin et al. [2016]) . . . . . . . 14

1.4 SEM image of copper nanowires synthesized at $60{ }^{\circ} \mathrm{C}$ (Mardiansyah et al.

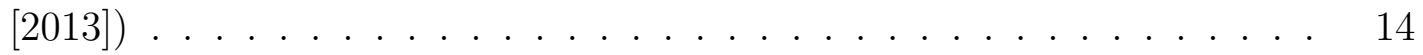

1.5 SEM image of copper nanoparticles without EDA (Tan and Balela [2017]) 16

1.6 Tapering and thickening growth of copper nanowire (Ye et al. [2014a]) . . 17

1.7 EDX mapping images of $\mathrm{Cu}-\mathrm{Au}$ nanowire: (a) $\mathrm{Cu}$ and (b) $\mathrm{Au}$ (Niu et al.

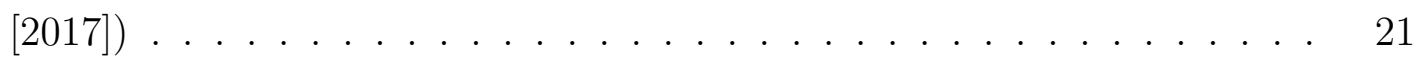

1.8 EDX mapping images of Cu-Pt nanowire (Chen et al. [2014]) . . . . . . 21

1.9 EDX mapping images of $\mathrm{Cu}-\mathrm{Ni}$ nanowire (Rathmell et al. [2012]) $\ldots .22$

1.10 EDX mapping images of $\mathrm{Cu}-\mathrm{Ag}$ nanowire: (a) $\mathrm{Cu}$ and (b) $\mathrm{Ag}$ (Zhao et al.

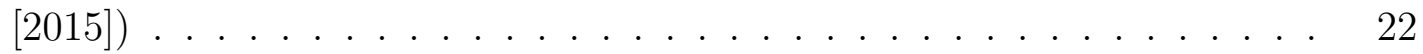

2.1 Synthesis process of copper nanowire . . . . . . . . . . . . . . 29 
2.2 SEM images of copper nanowires with $15 \mu \mathrm{l}$ of $\mathrm{N}_{2} H_{4} \ldots \ldots . . . . . .34$

2.3 SEM image of copper nanowires with $30 \mu \mathrm{l}$ of $\mathrm{N}_{2} \mathrm{H}_{4} \ldots \ldots$. . . . . . 35

2.4 SEM image of copper nanoparticles with $240 \mu$ l of $\mathrm{N}_{2} H_{4} \quad \ldots \ldots$

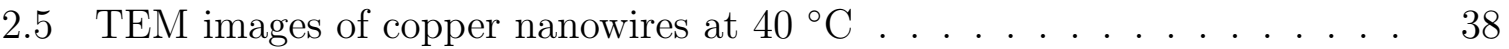

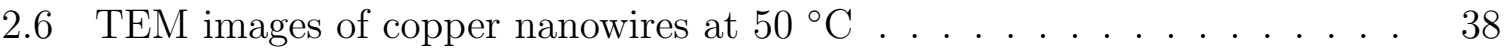

2.7 TEM images of copper nanowires at $60{ }^{\circ} \mathrm{C} \ldots . . \ldots 39$

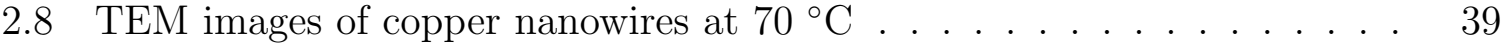

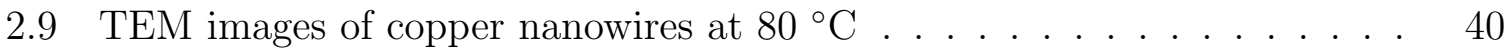

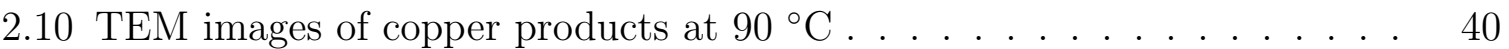

2.11 TEM images of copper nanowires with $15 \mu$ l of EDA . . . . . . . . . 42

2.12 TEM images of copper nanowires $50 \mu \mathrm{l}$ of EDA . . . . . . . . . . . 42

2.13 TEM images of copper nanowires $60 \mu \mathrm{l}$ of EDA . . . . . . . . . . . 43

2.14 TEM images of copper nanowires with $5 \mathrm{M}$ of $\mathrm{NaOH} \ldots . . . . . .45$

2.15 TEM images of copper nanowires with $7 \mathrm{M}$ of $\mathrm{NaOH} \ldots . . . . . .45$

2.16 TEM images of copper nanowires with $9 \mathrm{M}$ of $\mathrm{NaOH} \ldots . . . . . .46$

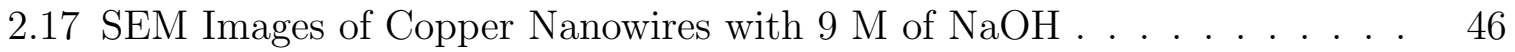

2.18 TEM images of copper nanowires with $12 \mathrm{M}$ of $\mathrm{NaOH} \quad \ldots . . . . . .47$

2.19 TEM images of copper nanowires with $37.2 \mathrm{mM}$ of copper precursor . . . 48

3.1 Fabrication process of $\mathrm{Cu}-\mathrm{Ag}$ nanowires . . . . . . . . . . . 54

3.2 SEM images of $\mathrm{Cu}-\mathrm{Ag}$ nanowires . . . . . . . . . . . . 56 
3.3 TEM image of $\mathrm{Cu}-\mathrm{Ag}$ nanowires . . . . . . . . . . . . . . . 56 


\section{Chapter 1}

\section{Introduction}

\subsection{Background}

With the rapid growth of Internet of Things (IoT), flexible electronics become one of the most exciting and promising technologies for prospective applications such as foldable tablets and phones, bendable photovoltaic cells, bendable light emitting

diodes (LEDs), and wearable sensors. Transparent electrodes are essential component for these electronics requiring low resistance electrical contacts without blocking light. Traditionally, indium tin oxide (ITO) was used as transparent conductor for a variety of applications such as flat-panel display, touch screen (Zhang et al. [2018a]), and solar cells because of its high conductivity, low resistance, and high transmittance (Guo et al. [2013]; Wang et al. [2018]). However, ITO is brittle, expensive, and rare material on earth (Hwang et al. [2016]). When ITO is used on the flexible electronics, the substrate can crack while bending or stretching force is applied. Those cracks not only degrade the conductivity, but also cause device reliability issue. The poor reserves of material, coupled with significant increase in demand, may make it difficult 
to produce with cost-effective and large-scale (Naghdi et al. [2018]).

Therefore, new materials are needed to overcome drawbacks of ITO while matintaining conductivity in the future. Several nanomaterials are promising candidate as alternatives to ITO, including carbon nanotubes (CNTs), graphene, and metal nanowires (Koo et al. [2016]; Zhang et al. [2012]; Rathmell and Wiley [2011]). This is because the reduced dimensions of material have an impact on device performance (Vaseashta and Malinovska [2005]). Table 1.1 summarizes the physical properties of potential transparent electrodes including transmittance, sheet resistance, and their flexibility. As shown in Table 1.1, CNTs and graphene are not proper as alternatives material because of their relatively low optoelectronic performance and low conductivity compared with ITO (Nam and Lee [2016]).

Table 1.1: Physical properties of potential transparent electrodes (Hsu et al. [2013]; Hu et al. [2011]; Lee et al. [2012])

\begin{tabular}{|c|c|c|c|}
\hline Material & Transmittance (\%) & Sheet Resistance $\Omega /$ sq & Flexibility \\
\hline ITO & 90 & 20 & No \\
\hline CNT & 80 & 150 & Yes \\
\hline Graphene & 80 & 200 & Yes \\
\hline Gold Nanowire & 95 & 7.2 & Yes \\
\hline Silver Nanowire & 90 & 10 & Yes \\
\hline Copper Nanowire & 90 & 34.8 & Yes \\
\hline
\end{tabular}


Metal nanowires with superior properties including transmittance and sheet resistance to ITO stood out as the promising alternative materials (Jason et al. [2015]). Conductive metal nanowires play a vital role in fabricating flexible conductor with small dimension. Nanowires as one-dimensional (1D) nanomaterials have nanometer $(\mathrm{nm})$ size of diameter and micrometer $(\mu \mathrm{m})$ size of length with both high flexibility and high transmittance while at the same time retaining a superior conductivity (Kumar et al. [2015]). Their shape and dimension can be controlled through the synthesis process.

Among the listed metal nanowires as shown in Table 1.1, silver and copper nanowires have comparable electrical properties on ITO (Wang and Ruan [2016]). However, the application of silver nanowire is still challenging because of its high cost (Zhao et al. [2016]). It is very challenging to manufacture nanowires massively. Copper nanowires receive tremendous attention for the flexible interconnect because of the combination of high performance and low cost (Ruan et al. [2016]). Copper has a conductivity of only $6 \%$ less than silver, and has the second lowest resistivity in metal materials (Ding et al. [2018]). In addition, it has extremely high reserves and 100 times less expensive than silver (Duong and Kim [2017]; Ye et al. [2014a]; Ye et al. [2016]). Furthermore, copper nanowires can be easily synthesized at the low temperature with not only saving time but also cost-effective because copper, as metal precursor in synthesis method, is inexpensive (Tran et al. [2017]). Therefore, its nanowire can be fabricated with significantly low cost and superior properties. 
However,once the copper nanowires are exposed to ambient condition, the formation of thin layer of copper oxide on the surface of the nanowires significantly decreased electrical properties (Wei et al. [2015]; Mardiansyah et al. [2018]). The formation of oxidation-resistant metallic shell on the copper nanowire is an effective way to prevent the oxidation of copper nanowire. Among metals, nickel (Ni), platinum $(\mathrm{Pt})$, gold $(\mathrm{Au})$, and silver $(\mathrm{Ag})$ are suitable for shell metal because those have the low resistivity and high electrical conductivity. Even if silver oxide is generated, it has much more electrical conductivity than copper oxide (Luo et al. [2013]). Therefore, it is of great interest to develop core-shell (copper-silver) structured nanowire instead of pure silver nanowire to achieve the effect of low cost while retaining superior conductivity.

\subsection{Literature review}

\section{Copper Nanowire Properties and Applications}

Copper nanowires have been become as one of the promising alternatives for next generation competed with the conventional conductive material and other metal nanowire including silver and gold (Zhao et al. [2016]). This is because copper nanowires have superior electrical resistivity $\left(1.673 \mu \Omega \cdot \mathrm{cm}\right.$ at $\left.20{ }^{\circ} \mathrm{C}\right)$ (Element [2019]), good flexibility, and being stretchable. The flexibility is one of the important components for fabrication of wearable electronic devices. Zhang et al. [2018b] have demonstrated 
the stretchable reliability of copper nanowires with the test of repeated stretching and releasing for applying to wearable stretchable sensor. This sensor was proved the current stability and high sensitivity with quick response. Copper nanowire transparent conductive electrodes have been applied to touch screen by Chu et al. [2016]. Due to high transmittance and low resistance, touch screen controlled easily the devices to turn on the light of LED. In addition, copper nanowires have been applied in various fields including solar cells, lithium-ion battery, and LEDs (Naghdi et al. [2018]; Bhanushali et al. [2015]).

\section{Synthesis of Copper Nanowire}

Various methods for growth of copper nanowires have been studied for a few decades, such as chemical vapor deposition (Choi and Park [2004]; Kim et al. [2008]), vacuum thermal decomposition (Haase et al. [2007]), the template-based method (Inguanta et al. [2009]; Gelves et al. [2006]; Pate et al. [2014]; Monson and Woolley [2003]), and the solution-based method (Wei et al. [2015]; Chang et al. [2005]; Nuryadin et al. [2016]) as shown in Figure 1.1.

The chemical vapor deposition method uses evaporation of copper precursor. Copper nanowire is stacked on the solid substrate at temperature between $200{ }^{\circ} \mathrm{C}-300$ ${ }^{\circ} \mathrm{C}$. This method is useful to grow vertically and laterally with well-aligned copper nanowire (Choi and Park [2004]; Kim et al. [2008]). However, this method requires high temperature and complex metal precursor of organometallic. The vacuum ther- 


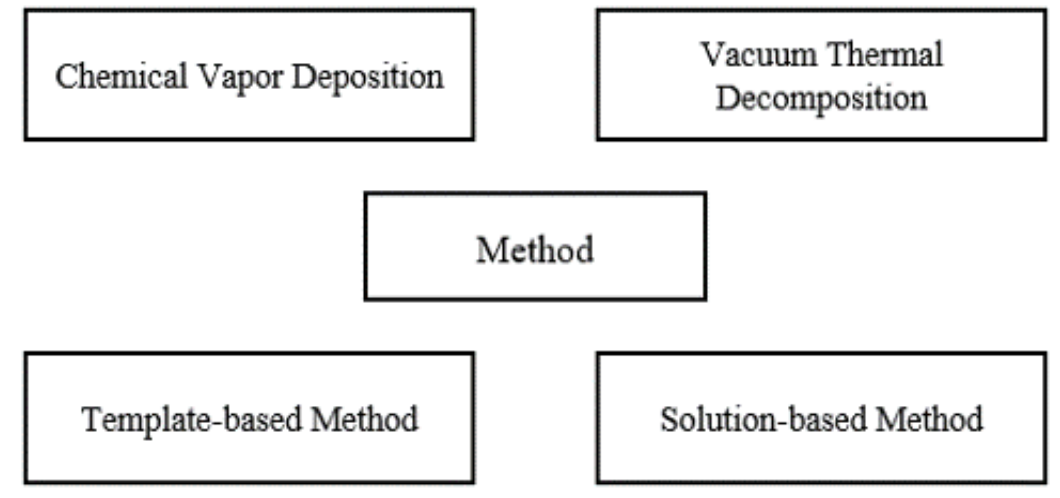

Figure 1.1: An overview of copper nanowire synthesis methods

mal decomposition process consists of heat treatments until evaporation of the copper precursor to be deposited in the sealed ampule under the low pressure and at various temperatures even $1100{ }^{\circ} \mathrm{C}$ (Haase et al. [2007]). The template-based method using different kind of templates can be employed to obtain copper nanowire at room temperature. This method is effective in controlling the dimension of nanowires. However, it requires electrode preparation, reusability of template, and longer reaction time (Inguanta et al. [2009]; Gelves et al. [2006]; Pate et al. [2014]; Monson and Woolley [2003]).

The solution-based method is mainly carried out by reducing copper precursor ions to obtain pure copper nanowires. This method has been considered one of the simplest and fastest ways to synthesize copper nanowires and has several advantages compared to others: 1) Low reaction temperature and short synthesis time, 2) Simple procedure, 3) Easy commercialization, 4) Use cheap metal precursor, 5) Relatively high yield, and 6) The dimensions of copper nanowires can be simply controlled by the 
ratio of capping and reducing agents (Kumar et al. [2015]; Kim et al. [2016]). However, the solution-based method allows contaminants to coexist in copper nanowire solution. However, these contaminants can be washed away with cleaning agent, such as methanol.

Table 1.2 summarizes advantages and disadvantages of the methods described above, which have been used to synthesize copper nanowires. In this study, copper nanowires were synthesized by using the solution-based method.

Table 1.2: An overview of copper nanowire synthesis methods

\begin{tabular}{|c|c|c|}
\hline Methodology & Advantage & Disadvantage \\
\hline $\begin{array}{c}\text { Chemical Vapor } \\
\text { Deposition }\end{array}$ & Well-aligned copper nanowire & $\begin{array}{c}\text { Need high temperature } \\
\text { Use an organometallic } \\
\text { Complicated procedure }\end{array}$ \\
\hline $\begin{array}{c}\text { Vacuum Thermal } \\
\text { Decomposition }\end{array}$ & $\begin{array}{c}\text { Easy to decompose an } \\
\text { organometallic }\end{array}$ & $\begin{array}{c}\text { Need high temperature } \\
\text { Complicated procedure }\end{array}$ \\
\hline Template-based & $\begin{array}{c}\text { Can be synthesized at room } \\
\text { temperature } \\
\text { Effective in handling dimension }\end{array}$ & $\begin{array}{c}\text { Complexity of electrode } \\
\text { preparation } \\
\text { Longer reaction time }\end{array}$ \\
\hline Solution-based & $\begin{array}{c}\text { Simple synthesis procedure } \\
\text { Fewer restrictions for the choice } \\
\text { of copper precursor } \\
\text { Practical condition including } \\
\text { reaction temperature and time } \\
\text { Easy commercialization }\end{array}$ & $\begin{array}{c}\text { Use a toxic chemical } \\
\text { Can be contaminated by } \\
\text { other chemicals }\end{array}$ \\
& \begin{tabular}{c} 
\\
\hline
\end{tabular} & \\
\hline
\end{tabular}


For the solution-based method, capping agents, which are used to grow nanowire in constant direction, and reducing agents, which are used to reduce metal ions are required (Ye et al. [2014b]). The synthesis of copper nanowires by the solution-based method was produced with different copper precursors, capping agents, and reducing agents as shown in Tables 1.3 and 1.4. The precursor of copper nitrate $\left(\mathrm{Cu}\left(\mathrm{NO}_{2}\right)_{3}\right)$ and copper chloride $\left(\mathrm{CuCl}_{2}\right)$ are mainly used as copper precursor. Chang et al. [2005] conducted research for first time to synthesize copper nanowire by reducing copper ions using hydrazine $\left(\mathrm{N}_{2} \mathrm{H}_{4}\right)$ as the reducing agent in the solution, which was contained ethylenediamine (EDA) as the capping agent, in the solvent of deionized water (DI $\mathrm{H}_{2} \mathrm{O}$ ). Since then, many researchs have been conducted on how to control the formation of copper nanowires with the $\mathrm{N}_{2} \mathrm{H}_{4}$ as reducing agent and EDA as capping agent as shown in Table 1.3. Rathmell et al. [2010] implemented synthesis of copper nanowires to prove large scale in the solution by developing approach conducted by Chang et al. [2005]. 1.2g of copper nanowires were obtained with increasing of experimental condition and such copper nanowires were formed with spherical nanoparticle at the one end of copper nanowires as shown in Figure 1.2. The synthesis conditions and the dimensions of synthesized copper nanowires based on EDA and $\mathrm{N}_{2} \mathrm{H}_{4}$ are summarized in Table 1.3. As shown in Table 1.3, with EDA and $\mathrm{N}_{2} H_{4}$, copper nanowires can be formed at relatively lower temperature compared with other capping agents and reducing agents.

Table 1.4 shows the dimensions of synthesized copper nanowires under different 


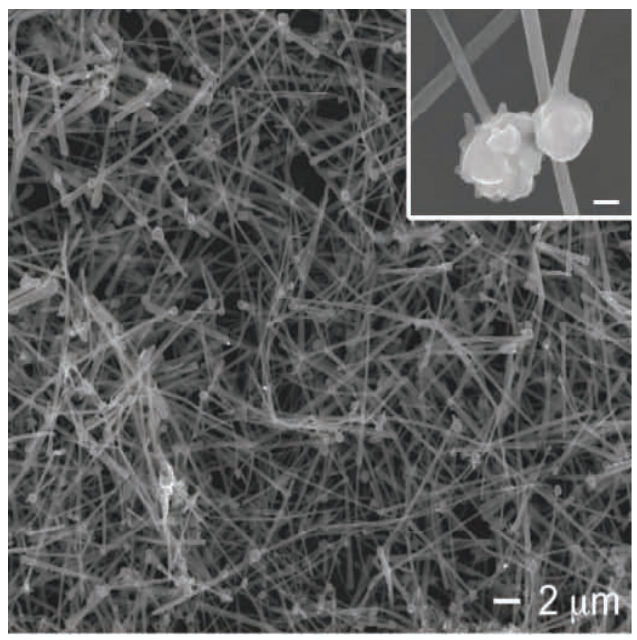

Figure 1.2: SEM image of copper nanowire reported by Rathmell et al. [2010] showing the presence of spherical seed on one end of the nanowires

Table 1.3: The effect of synthesis temperature and time on dimensions of copper nanowire with EDA and $\mathrm{N}_{2} H_{4}$ showing higher synthesis temperature resulted in shorter length

\begin{tabular}{|c|c|c|c|c|c|}
\hline $\begin{array}{c}\text { Copper } \\
\text { Precursor }\end{array}$ & $\begin{array}{c}\text { Capping } \\
\text { Agent }\end{array}$ & $\begin{array}{c}\text { Reducing } \\
\text { Agent }\end{array}$ & Condition & $\begin{array}{c}\text { Dimension } \\
\text { (Diameter/Length) }\end{array}$ & Ref. \\
\hline $\mathrm{Cu}\left(\mathrm{NO}_{2}\right)_{3}$ & EDA & $\mathrm{N}_{2} H_{4}$ & $60^{\circ} \mathrm{C}, 15 \mathrm{~h}$ & $90-120 \mathrm{~nm} / 40-50 \mu \mathrm{m}$ & $\begin{array}{c}\text { Chang et al. } \\
{[2005]}\end{array}$ \\
\hline $\mathrm{Cu}\left(\mathrm{NO}_{2}\right)_{3}$ & EDA & $\mathrm{N}_{2} H_{4}$ & $80^{\circ} \mathrm{C}, 1 \mathrm{~h}$ & $90 \pm 10 \mathrm{~nm} / 10 \pm 3 \mu \mathrm{m}$ & $\begin{array}{c}\text { Rathmell et al. } \\
{[2010]}\end{array}$ \\
\hline $\mathrm{Cu}\left(\mathrm{NO}_{2}\right)_{3}$ & EDA & $\mathrm{N}_{2} H_{4}$ & $60^{\circ} \mathrm{C}$, & Aspect ratio: $120 \pm 30$ & $\begin{array}{c}\text { Harsojo et al. } \\
{[2017]}\end{array}$ \\
\hline $\mathrm{Cu}\left(\mathrm{NO}_{2}\right)_{3}$ & EDA & $\mathrm{N}_{2} H_{4}$ & $60^{\circ} \mathrm{C}, 1 \mathrm{~h}$ & $90 \mathrm{~nm} / 50 \mu \mathrm{m}$ & $\begin{array}{c}\text { Tan and } \\
\text { Balela [2017] }\end{array}$ \\
\hline $\mathrm{Cu}\left(\mathrm{NO}_{2}\right)_{3}$ & EDA & $\mathrm{N}_{2} H_{4}$ & $80^{\circ} \mathrm{C}, 1 \mathrm{~h}$ & $70 \mathrm{~nm} / 3.7 \mu \mathrm{m}$ & $\begin{array}{c}\text { Nuryadin } \\
\text { et al. [2016] }\end{array}$ \\
\hline $\mathrm{Cu}\left(\mathrm{NO}_{2}\right)_{3}$ & EDA & $\mathrm{N}_{2} H_{4}$ & $60^{\circ} \mathrm{C}, 1 \mathrm{~h}$ & $101 \mathrm{~nm} / 21 \mu \mathrm{m}$ & $\begin{array}{c}\text { Mardiansyah } \\
\text { et al. [2013] }\end{array}$ \\
\hline
\end{tabular}


Table 1.4: Various capping and reducing agents reported to be used for synthesis of copper nanowire

\begin{tabular}{|c|c|c|c|c|c|}
\hline $\begin{array}{c}\mathrm{Cu} \\
\text { Precursor }\end{array}$ & $\begin{array}{l}\text { Capping } \\
\text { Agent }\end{array}$ & $\begin{array}{c}\text { Reducing } \\
\text { Agent }\end{array}$ & Condition & $\begin{array}{l}\text { Dimension } \\
\text { (Diameter/Length) }\end{array}$ & Ref. \\
\hline $\mathrm{Cu}\left(\mathrm{NO}_{2}\right)_{3}$ & EDA & Cathechin & $80^{\circ} \mathrm{C}, 1 \mathrm{~h}$ & $100 \pm 15 \mathrm{~nm} / 6 \pm 4 \mu \mathrm{m}$ & $\begin{array}{l}\text { Periasamy } \\
\text { et al. [2013] }\end{array}$ \\
\hline $\mathrm{Cu}\left(\mathrm{NO}_{2}\right)_{3}$ & $\begin{array}{l}\text { Polyvinyl- } \\
\text { prrolidone } \\
\text { Cetyltri- } \\
\text { methyla- } \\
\text { mmonium } \\
\text { Chloride }\end{array}$ & $\begin{array}{c}\text { Ethylene } \\
\text { Glycol }\end{array}$ & $189^{\circ} \mathrm{C}, 4 \mathrm{~h}$ & $60 \mathrm{~nm} / 40 \mu \mathrm{m}$ & $\begin{array}{c}\text { Huaman et al. } \\
\text { [2018] }\end{array}$ \\
\hline $\mathrm{CuCl}_{2}$ & $\begin{array}{l}\text { Oleic } \\
\text { Acid/ } \\
\text { Oley- } \\
\text { lamine }\end{array}$ & Glucose & $\begin{array}{c}116^{\circ} \mathrm{C} \\
12 \mathrm{~h}\end{array}$ & $45 \pm 3 \mathrm{~nm} / 60-90 \mu \mathrm{m}$ & Li et al. [2014] \\
\hline $\mathrm{CuCl}_{2}$ & $\begin{array}{l}\text { Hexanedi- } \\
\text { amine }\end{array}$ & Glucose & $100^{\circ} \mathrm{C}, 6 \mathrm{~h}$ & $24 \pm 4 \mathrm{~nm}$ & $\begin{array}{c}\text { Jin et al. } \\
{[2011]}\end{array}$ \\
\hline $\mathrm{CuCl}_{2}$ & $\begin{array}{l}\text { Oleyl- } \\
\text { amine }\end{array}$ & Trisilane & $\begin{array}{c}165^{\circ} \mathrm{C} \\
10 \mathrm{~h}\end{array}$ & $17.5 \mathrm{~nm} / 17 \mu \mathrm{m}$ & $\begin{array}{l}\text { Cui et al. } \\
\text { [2015] }\end{array}$ \\
\hline $\mathrm{CuCl}_{2}$ & $\begin{array}{l}\text { polyethyl- } \\
\text { eneimine }\end{array}$ & $\begin{array}{l}\text { Ascorbic } \\
\text { Acid }\end{array}$ & $90^{\circ} \mathrm{C}, 3 \mathrm{~h}$ & $\begin{array}{c}472.9 \pm 100.3 \mathrm{~nm} / \\
142.14 \pm 42.6 \mu \mathrm{m}\end{array}$ & $\begin{array}{l}\text { Tang et al. } \\
\quad[2015]\end{array}$ \\
\hline $\mathrm{CuCl}_{2}$ & $\begin{array}{l}\text { Oleyl- } \\
\text { amine }\end{array}$ & $\begin{array}{l}\text { Acsorbic } \\
\text { Acid }\end{array}$ & $79^{\circ} \mathrm{C}, 12 \mathrm{~h}$ & $134 \pm 4 \mathrm{~nm} / 40 \pm 2 \mu \mathrm{m}$ & $\begin{array}{l}\text { Mock et al. } \\
\quad[2018]\end{array}$ \\
\hline $\mathrm{CuCl}_{2}$ & $\begin{array}{c}\text { Potassium } \\
\text { Bromide } \\
\text { / Oley- } \\
\text { lamine }\end{array}$ & $\begin{array}{c}\text { Ethylene } \\
\text { Glycol }\end{array}$ & $198^{\circ} \mathrm{C}, 1 \mathrm{~h}$ & $92 \mathrm{~nm} / 30 \mu \mathrm{m}$ & $\begin{array}{l}\text { Yin et al. } \\
{[2014]}\end{array}$ \\
\hline $\mathrm{CuCl}_{2}$ & $\begin{array}{l}\text { Cetrimo- } \\
\text { nium } \\
\text { Bromide }\end{array}$ & $\begin{array}{c}\text { Sodium } \\
\text { Borohy- } \\
\text { dride }\end{array}$ & $\begin{array}{c}180^{\circ} \mathrm{C} \\
12 \mathrm{~h}\end{array}$ & $20 \mathrm{~nm} / 2 \mu \mathrm{m}$ & $\begin{array}{l}\text { Zhang and Cui } \\
{[2009]}\end{array}$ \\
\hline
\end{tabular}


each capping agents and reducing agents. Using ascorbic acid and glucose can overcome the drawback of $\mathrm{N}_{2} \mathrm{H}_{4}$ associated with safety problem, however, they required increasing reaction temperature of between $80{ }^{\circ} \mathrm{C}$ and $160{ }^{\circ} \mathrm{C}$ to reduce copper ions (Bhanushali et al. [2015];Rathmell et al. [2010]). In addition, other capping agents and reducing agents also require the relatively high reaction temperature and longer reaction time. In the case of using catechin instead of $\mathrm{N}_{2} H_{4}$ (Periasamy et al. [2013]), copper nanowires are synthesized at relatively low temperature and short reaction time, however, on average dimension of copper nanowires are inferior to using $\mathrm{N}_{2} H_{4}$. Copper nanowires using oleylamine and ascorbic acid are synthesized at relatively low temperature, however, it requires longer reaction time. Using oleylamine as capping agent requires combining with other capping agent such as oleic acid and potassium bromide (Li et al. [2014];Yin et al. [2014]). Jin et al. [2011] obtained copper nanowires with much smaller diameter of $24 \pm 4 \mathrm{~nm}$ and the length of hundred $\mu \mathrm{m}$ using hexanediamine as capping agent in the presence of glucose as reducing agent. However, these nanowires caused tangle, and revealed lower conductivity (Zhang et al. [2012]).

Koo et al. [2016] demonstrated the relationship between EDA as capping agent and copper nanowire oxidation, as a result, EDA played a role of reducing hydroxide adsorption to increase the resistivity of oxidation of copper nanowire. Therefore, in this study, EDA as capping agent, which can reduce the copper nanowire oxidation rate, and $\mathrm{N}_{2} H_{4}$, which is well-known as strong reducing agent, are used and they enable to synthesize copper nanowires under mild conditions regarding the relatively 
lower reaction temperature and shorter reaction time.

\section{Copper Nanowire Growth Mechanism}

In order to control the quality of copper nanowires, the parameters including capping agent and reducing agent play vital roles. In the solution-based method, copper precursor and reagent occur the chemical reaction to form copper hydroxide $\left(\mathrm{Cu}(\mathrm{OH})_{2}\right)$ (Ye et al. [2016]). As a capping agent, EDA is an essential chemical not only to prevent the precipitation and aggregation of $\mathrm{Cu}(\mathrm{OH})_{2}$ from being generated in the aqueous solution for properly forming copper oxide $\left(\mathrm{Cu}_{2} \mathrm{O}\right)$ nanoparticles but also to inhibit charge transfer of copper complexation by covering the surface of $\mathrm{Cu}(\mathrm{OH})_{2}$ on the growing crystal plane (Bhanushali et al. [2015]). This is because the surface energy on the facets generally affect the shape of crystal (Kumar et al. [2015]). The stabilized hydroxide ions by EDA supply appropriate environment for redox process of copper ions. By adding $\mathrm{N}_{2} \mathrm{H}_{4}$ as reducing agent, $\mathrm{Cu}(\mathrm{OH})_{2}$ and small quantity of $\mathrm{Cu}_{2} \mathrm{O}$ nanoparticles coexist in the solution. However, copper ions in $\mathrm{Cu}_{2} \mathrm{O}$ are further reduced to copper atoms (Ye et al. [2016]). The nucleation is generated by adding $\mathrm{N}_{2} H_{4}$, which guides to homogeneous nucleation in the solution, and these nuclei play roles as copper seeds (Bhanushali et al. [2015]). In addition, the rate of nucleation is increased at high temperature (Rathmell [2013]). However, since the growth of copper nanowires can be generated by forming crystallization, which includes the formation of solid-state structure through nucleation, adjusting nucleation at the be- 
ginning stage of crystallization is an important for preventing copper nanowires from being defected (Lin et al. [2018]; Bhanushali et al. [2015]). Therefore, sufficient EDA provides to form stable hydroxide ions that lead to well-ordered copper nanowires by reducing copper ions through $\mathrm{N}_{2} H_{4}$.

\section{The Effect of Temperature on the Copper Nanowire Growth}

Nuryadin et al. [2016] studied on the effect of temperature on growth of copper nanowire by comparing their dimension. In their work, copper nanowires in the aqueous solution were grown at $4{ }^{\circ} \mathrm{C}, 30{ }^{\circ} \mathrm{C}$, and $80{ }^{\circ} \mathrm{C}$. Especially, high yield of copper nanowires was obtained above room temperature as shown in Figure 1.3. As the reaction temperature increased, the diameter became thinner, however, the length decreased. The diameter and length of copper nanowire synthesized at $80{ }^{\circ} \mathrm{C}$ were $70 \mathrm{~nm}$ and $3.7 \mu \mathrm{m}$, respectively. In addition, lower resistance was obtained in copper nanowire synthesized at $80{ }^{\circ} \mathrm{C}$ compared to others temperatures. Mardiansyah et al. [2013] have synthesized high yield copper nanowires at $60{ }^{\circ} \mathrm{C}$ as shown in Figure 1.4. These copper nanowires showed thicker diameter and longer length, which were $101 \mathrm{~nm}$ and $21 \mu \mathrm{m}$, respectively, compared with the dimensions of copper nanowires synthesized at $80{ }^{\circ} \mathrm{C}$ by Nuryadin et al. [2016]. 


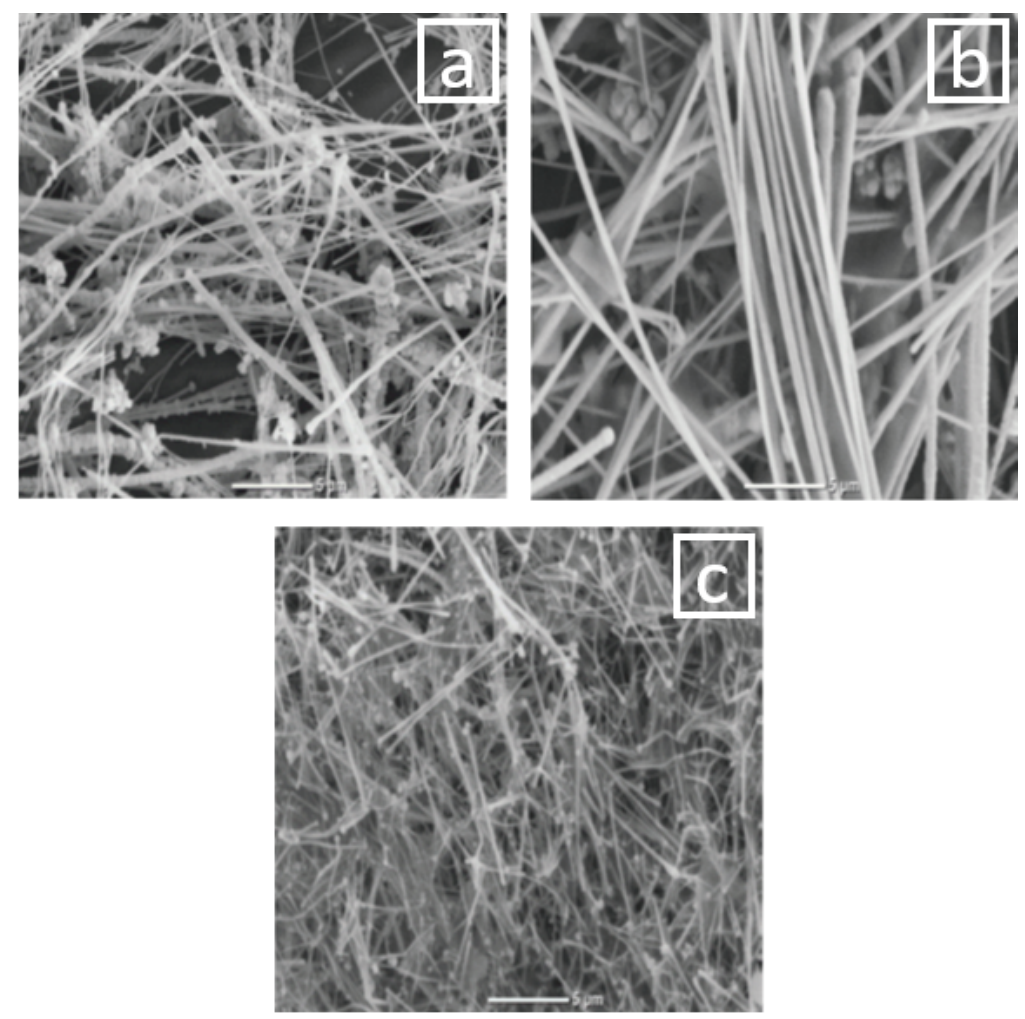

Figure 1.3: SEM images of copper nanowires synthesized at various temperature: (a) $4{ }^{\circ} \mathrm{C}$, (b) $30^{\circ} \mathrm{C}$, and (c) $80^{\circ} \mathrm{C}$ (Nuryadin et al. [2016])

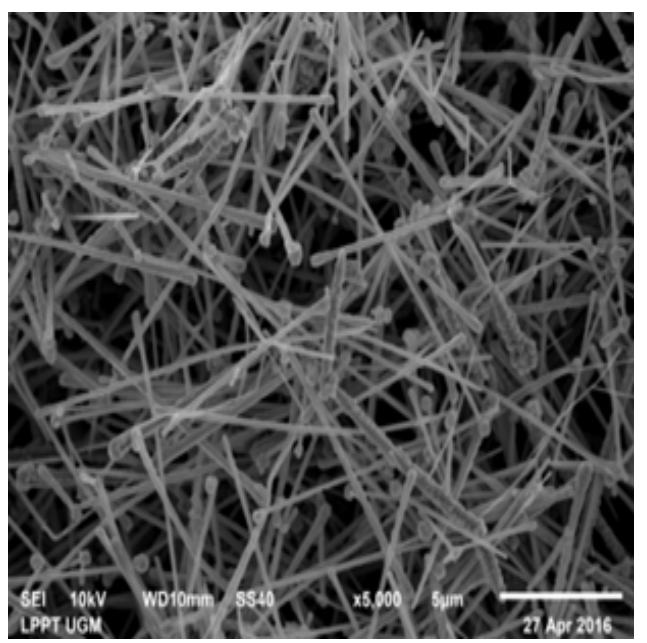

Figure 1.4: SEM image of copper nanowires synthesized at $60{ }^{\circ} \mathrm{C}$ (Mardiansyah et al. [2013]) 


\section{The Effect of Capping Agent on the Copper Nanowire Growth}

EDA plays one of the important roles for growth and controlling the shape of copper nanowires (Kim et al. [2008]). EDA supports to reduce free copper ions in aqueous solution. It is helpful for growth direction of copper nanowire. In addition, the amine group contained EDA allows copper ions to bind to the surface of copper nanostructure in the aqueous solution (Xu et al. [2014]). Tan and Balela [2017] investigated the effect of EDA as capping agent on morphology of copper nanowires. In absence of EDA, large and erratic copper nanoparticles were only observed as shown in Figure 1.5. When small amount of EDA was added, copper nanowires began to produce with copper seeds at one end, and increasing the amount of EDA made good quality of copper nanowires. However, further increasing the concentration of EDA caused nanowires too short even nanorod. Copper nanowires synthesized with the insufficient amount of EDA lead to lose original metal properties (Ye et al. [2014c]). 


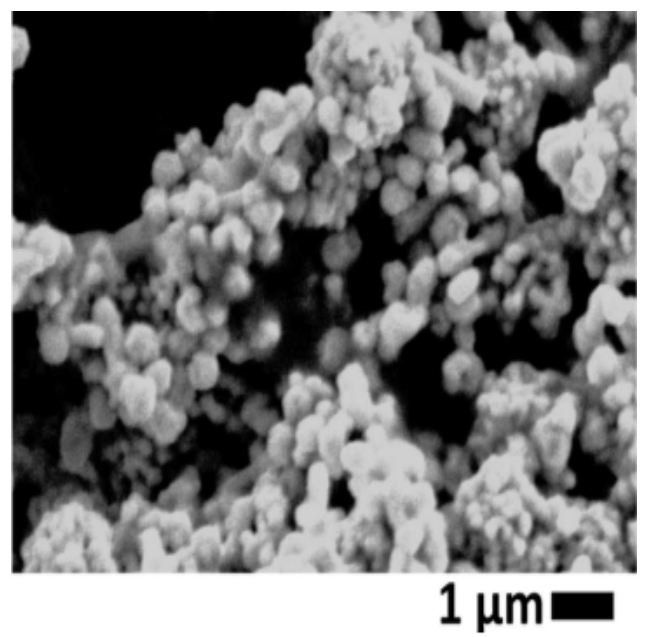

Figure 1.5: SEM image of copper nanoparticles without EDA (Tan and Balela [2017])

\section{The Effect of Reducing Agent on the Copper Nanowire Growth}

As a strong reducing agent, $\mathrm{N}_{2} H_{4}$ is generally used to reduce copper ions to copper atom (Jin et al. [2011]). Harsojo et al. [2017] investigated the effect of concentration of $\mathrm{N}_{2} \mathrm{H}_{4}$ on growth of copper nanowire and demonstrated that the excess of $\mathrm{N}_{2} \mathrm{H}_{4}$ induced thicker diameter and shorter length of copper nanowire accompanied with copper nanoparticles. In comparison to the effect of concentration of EDA, the dimension of copper nanowires is more sensitive to the concentration of $\mathrm{N}_{2} H_{4}$. As shown in Figure 1.6, copper nanowires, which have begun to grow in tapered shape, undergo a process of thickening after adding $\mathrm{N}_{2} H_{4}$ while maintaining tapered shape (Ye et al. [2014a]). Therefore, the addition of $\mathrm{N}_{2} H_{4}$ cannot change the shape of copper nanowires, which is determined by EDA. However, the thickness could be adjusted depending on the concentration of $\mathrm{N}_{2} \mathrm{H}_{4}$. 


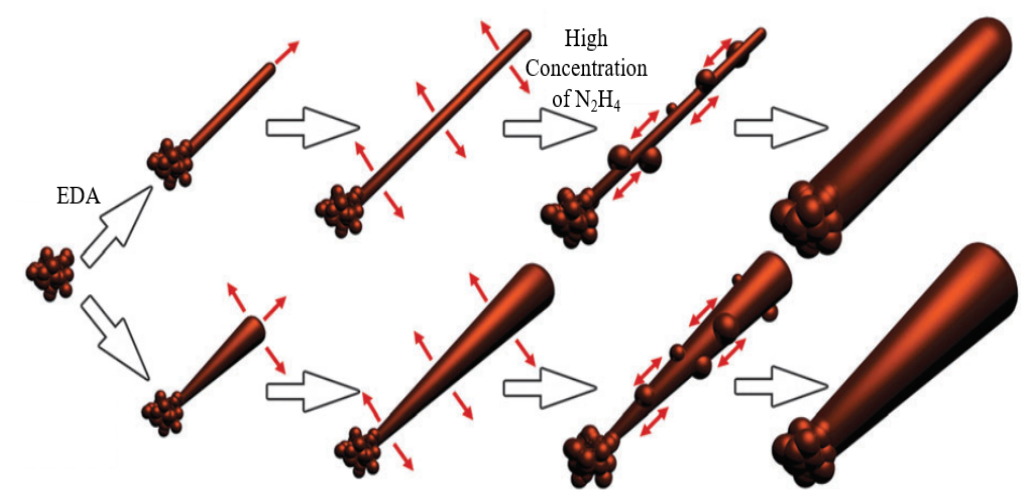

Figure 1.6: Tapering and thickening growth of copper nanowire (Ye et al. [2014a])

\section{The Effect of Metal Precursor on the Copper Nanowire Growth}

Mardiansyah et al. [2013] investigated the effect of molar ratio of copper precursor, copper nitrate $\left(\mathrm{Cu}\left(\mathrm{NO}_{3}\right)_{2}\right)$, under different molar ratios conditions. The high molar ratio caused composite of copper nanoparticles and nanowires. However, copper nanoparticles were dominantly observed. On the other hand, as molar ratio of copper precursor is decreased, the dimension of copper nanowires becomes thinner and longer and the yield of copper nanowires is increased. Moreover, decreasing molar ratio also changes copper nanoparticles to copper nanowires. However, $\mathrm{Cu}\left(\mathrm{NO}_{3}\right)_{2}$ as copper precursor tends to be weak in dispersing copper nanowires evenly in the solution (Zhang et al. [2012]). 


\section{Core-Shell Copper Nanowire Synthesis}

Copper oxide layers are usually formed on the surface of coppers. Unlike aluminium oxide $\left(\mathrm{Al}_{2} \mathrm{O}_{3}\right)$ on the surface of aluminium, the copper oxide layers cannot behave as passivated layers to prevent further oxidation of copper nanowires (Liu and Zhou [2005]). In addition, the irregular surface of copper nanowire is susceptible to defects, which would cause dangling chemical bond on the surface of copper nanowire, and dangling bond is significantly sensitive to the ambient condition, which results in the oxidation of copper nanowire, while reducing surface energy (Xu et al. [2016]).

Core-shell structured nanowires are considered as an effective way to prevent copper nanowires from being oxidized. The electroplating method and the galvanic replacement method are generally used to fabricate core-shell copper nanowire. The electroplating method is basically carried out with the copper nanowire film as working electrode, which is placed on negative potential, and metal ions, which is placed on positive potential, is coated on the surface of copper nanowire (Ye et al. [2016]). The electroplating method enables to control the thickness of shells and prevents metal shells deposition from aggregating, and is used for the wide range of metal including Ni, Pt, and Au (Chen et al. [2013]). However, it is low efficiency because of non-uniformly plating on entire film and dependent on instrument, and it cannot be conducted with only copper nanowire. The galvanic replacement method is to replace the surface of core metal with shell metal through the oxidation of metal by ions 
with having high reduction potential (Lee et al. [2015]). The galvanic replacement method provides a simple and diverse ways to multifunctional nanostructures due to its control ability of size and shape including interior structure and morphology (Xia et al. [2013]). However, when plating shell metal with higher reduction potential than copper, copper nanowires can be corroded or broken, leading to increase in resistance (Ye et al. [2016]; Xia et al. [2013]). Therefore, the control of reductant concentration is required to be considered to prevent this issue (Zhao et al. [2016]).

When a thin layer as shell material, such as $\mathrm{Au}, \mathrm{Pt}, \mathrm{Ni}$, and $\mathrm{Ag}$, is placed on the surface of copper nanowire, Niu et al. [2017] synthesized of $\mathrm{Cu}-\mathrm{Au}$ nanowires through the growth of the atomic layer of Au precursor at $140{ }^{\circ} \mathrm{C}$. In addition, as shown in Figure 1.7, they have demonstrated the smooth surface of shell with the property of stability of $\mathrm{Cu}-\mathrm{Ag}$ nanowires under exposure in the ambient condition during over 700 hours. However, the fabrication of $\mathrm{Cu}-\mathrm{Au}$ nanowire is required a high temperature over $100{ }^{\circ} \mathrm{C}$ and is difficult to achieve low cost because $\mathrm{Au}$ is a precious metal. Chen et al. [2014] employed Pt as shell metal to cover copper nanowire. In their synthesis process, $\mathrm{Cu}-\mathrm{Pt}$ nanowire was fabricated with rough surface as shown in Figure 1.8 by using the electroplating method and they optimized the Pt content to coat copper nanowire improving the oxidation stability of $\mathrm{Cu}-\mathrm{Pt}$ nanowire. Nonetheless, $\mathrm{Cu}-\mathrm{Pt}$ nanowire has high cost issue as well because $\mathrm{Pt}$ is also one of the expensive metals.

Rathmell et al. [2012] conducted the formation of $\mathrm{Cu}-\mathrm{Ni}$ nanowires using the twostep approach to investigate the effect of properties depending on $\mathrm{Cu}$ to $\mathrm{Ni}$ ratio. 
They demonstrated that the same ratio on $\mathrm{Cu}$ to $\mathrm{Ni}$ reduced the transmittance but increased the oxidation resistance, and the higher $\mathrm{Cu}$ ratio than $\mathrm{Ni}$ led to neutral color and great electro-optical performance. However, as shown in Figure 1.9, copper induced to shell metal on the surface of copper nanowire may cause an imperfection surface, resulting in weak stability of nanowire. Zhao et al. [2015] accomplished the fabrication of $\mathrm{Cu}-\mathrm{Ag}$ nanowire as shown in Figure 1.10, using solution contained polyvinylprrolidone (PVP) and silver salt. They performed the synthesis of bimetallic nanowire under various molar ratios of $\mathrm{Cu}$ to $\mathrm{Ag}$, proving the oxidation resistance. Jiang et al. [2016] developed well-dispersed silver nanoparticles on the surface of copper nanowires using galvanic replacement method and ammonium hydroxide $\left(\mathrm{NH}_{4} \mathrm{OH}\right)$ as solvent. According to their synthesis method, $\mathrm{Ag}\left(\mathrm{NH}_{3}\right)_{2}$ formed by dissolving silver with $\mathrm{NH}_{4} \mathrm{OH}$ solution reacted with copper atom that brought about deposition of silver nanoparticles on the surface of copper nanowires. However, the possibility of growth of silver nanorod also is mentioned in the case of the high ratio of $\mathrm{Cu}$ to $\mathrm{Ag}$. 


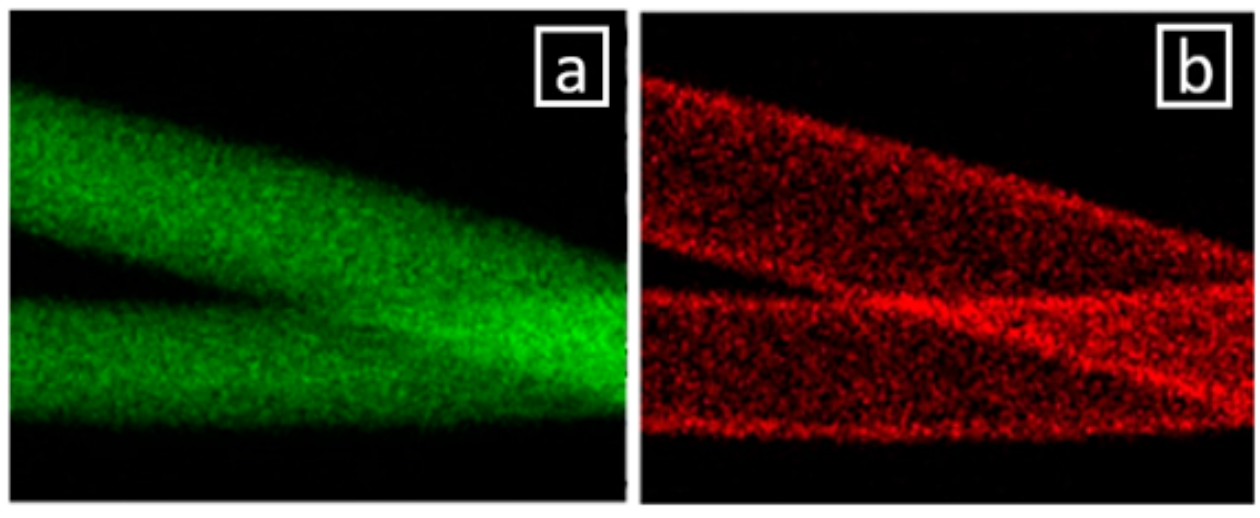

Figure 1.7: EDX mapping images of $\mathrm{Cu}-\mathrm{Au}$ nanowire: (a) $\mathrm{Cu}$ and (b) $\mathrm{Au}$ (Niu et al. [2017])
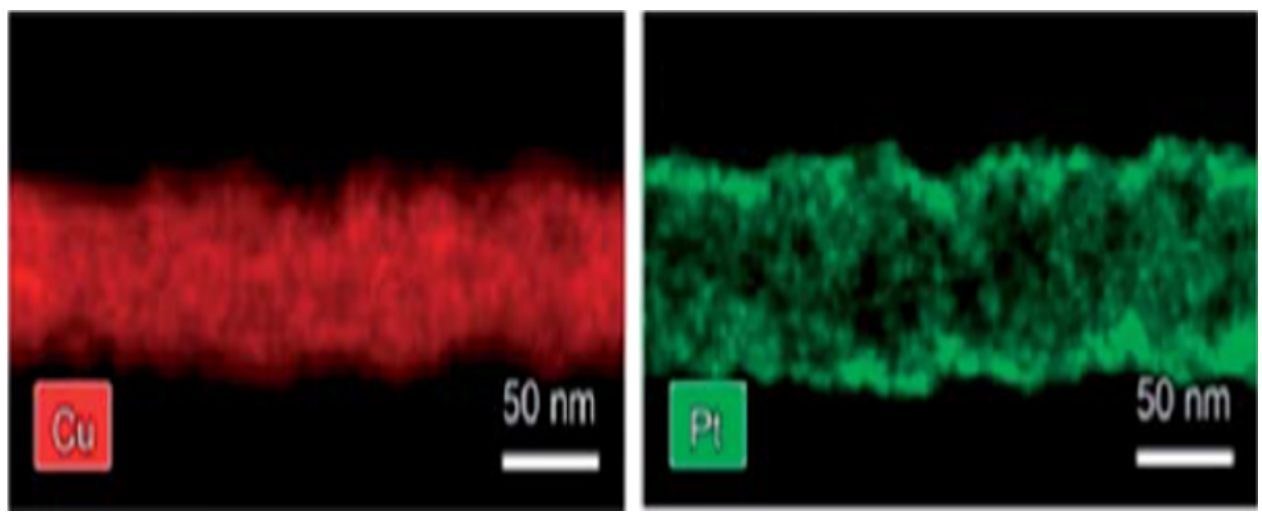

Figure 1.8: EDX mapping images of $\mathrm{Cu}-\mathrm{Pt}$ nanowire (Chen et al. [2014]) 


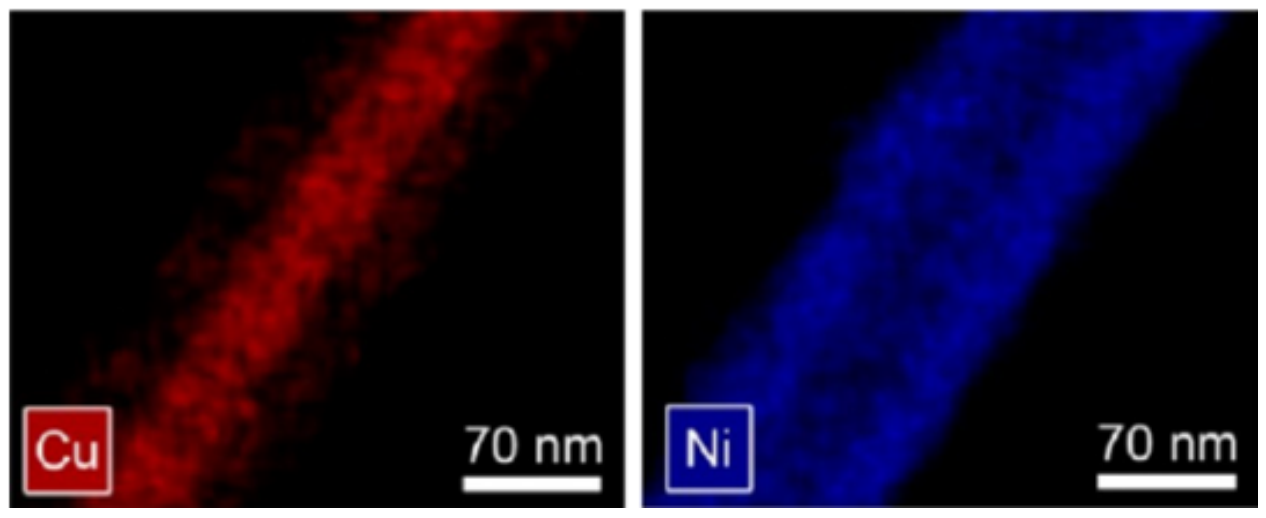

Figure 1.9: EDX mapping images of $\mathrm{Cu}-\mathrm{Ni}$ nanowire (Rathmell et al. [2012])

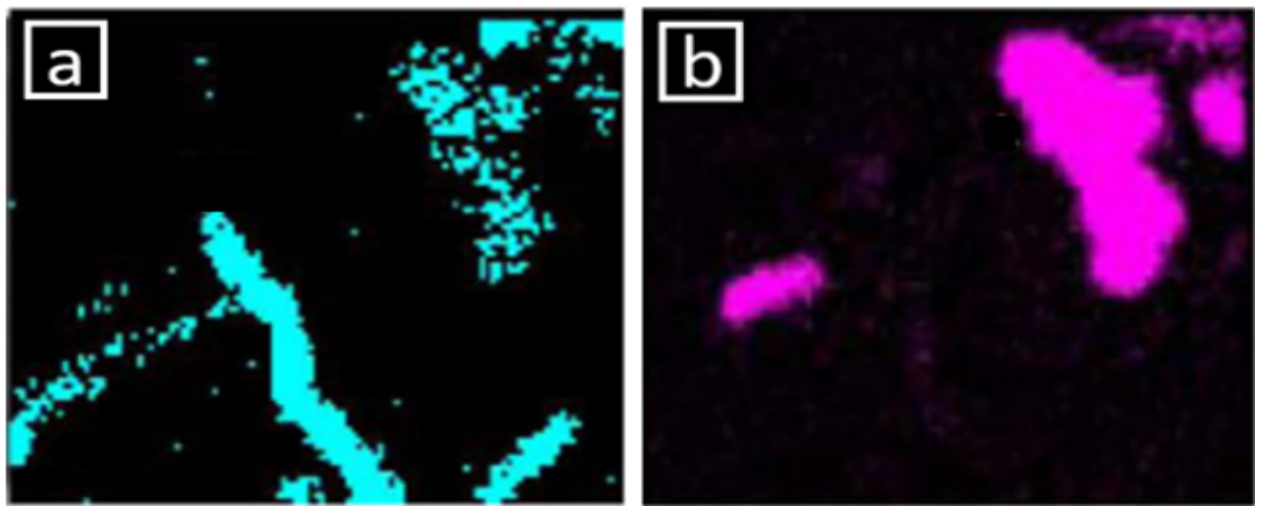

Figure 1.10: EDX mapping images of $\mathrm{Cu}-\mathrm{Ag}$ nanowire: (a) $\mathrm{Cu}$ and (b) $\mathrm{Ag}$ (Zhao et al. [2015]) 


\section{Oxidation Behavior of Core-Shell Copper Nanowire}

Coating on the surface of copper nanowire with other metals including silver can be significantly improved the oxidation behavior. Luo et al. [2013] compared the oxidation behavior of $\mathrm{Cu}-\mathrm{Ag}$ nanowires with copper nanowires under both temperature and time dependent conditions to demonstrate an effect of core-shell copper nanowires. The weight of copper nanowires and $\mathrm{Cu}-\mathrm{Ag}$ nanowires started to increase at $85{ }^{\circ} \mathrm{C}$ and $230{ }^{\circ} \mathrm{C}$, respectively, and maximum weight of copper nanowires and $\mathrm{Cu}-\mathrm{Ag}$ nanowires arrived at $298^{\circ} \mathrm{C}$ and $320^{\circ} \mathrm{C}$, respectively. The weight increasing rate per $1^{\circ} \mathrm{C}$ of copper nanowire was 2.7 times higher than that of $\mathrm{Cu}-\mathrm{Ag}$ nanowire and the total weight increasing rate of copper nanowire and $\mathrm{Cu}-\mathrm{Ag}$ nanowire was $20.3 \%$ and $3.2 \%$, respectively. In the time-dependent condition, the temperature was kept at $250{ }^{\circ} \mathrm{C}$ for 25 mins. The weight of copper nanowire increased rapidly as soon as reaching at $250^{\circ} \mathrm{C}$, while the weight of $\mathrm{Cu}-\mathrm{Ag}$ nanowire remain unchanged. The total weight increasing rate of copper nanowire was $16 \%$ and that of $\mathrm{Cu}-\mathrm{Ag}$ nanowire was $1.7 \%$ within 25 mins. Therefore, their results show that the oxidation of $\mathrm{Cu}-\mathrm{Ag}$ nanowire is proceeded at higher temperature with lower weight increasing rate and weight increasing rate of $\mathrm{Cu}-\mathrm{Ag}$ nanowire is much lower than that of copper nanowire. 


\section{Electrical Properties of Core-Shell Copper Nanowire}

Copper nanowires are susceptible to oxidation, which not only drastically reduces electrical conductivity, but also induces to be nonconductive. However, copper-based core-shell nanowires can delay oxidation of copper nanowire and prevent a reduction of electrical conductivity by covering with other metals as shell.

The effect of copper-based core-shell nanowire on sheet resistance and stability has been proven by Ye et al. [2016]. The sheet resistance of copper nanowires film exposed at $85^{\circ} \mathrm{C}$ started to increased steadily, however, it was dramatically increased right after 5 days. On the other hand, the sheet resistance of copper nanowires film exposed at $160{ }^{\circ} \mathrm{C}$ was quickly increased in a few hours. The sheet resistance of $\mathrm{Cu}-\mathrm{Ni}$ nanowires film at $85^{\circ} \mathrm{C}$ was quite stable over 30 days with increasing only $10 \Omega / \mathrm{sq}$ while displaying more oxidation resistance than copper nanowires. In addition, the sheet resistance of $\mathrm{Cu}-\mathrm{Ag}$ nanowires film at $160{ }^{\circ} \mathrm{C}$ was stable over 1 day, and no significant difference compared with silver nanowire.

The sheet resistance of $\mathrm{Cu}-\mathrm{Ag}$ nanowires on different silver coating thickness has been discussed by Stewart et al. [2015]. In their research, although the sheet resistance of $\mathrm{Cu}-\mathrm{Ag}$ nanowires with both $5 \mathrm{~nm}$ and $15 \mathrm{~nm}$ of silver shell thickness was slightly increased over $24 \mathrm{~h}$ at $160{ }^{\circ} \mathrm{C}$, it exhibited similar to the sheet resistance value of silver nanowires. However, $5 \mathrm{~nm}$ of silver shell thickness was shown unstably under humidity condition, $85{ }^{\circ} \mathrm{C} / 85 \%$ relative humidity $(\mathrm{RH})$, with increasing the sheet 
resistance of $\mathrm{Cu}-\mathrm{Ag}$ nanowires and copper core nanowires were not entirely protected against oxidation. On the other hand, stable sheet resistance over $24 \mathrm{~h}$ was obtained with $15 \mathrm{~nm}$ of silver shell thickness under $85{ }^{\circ} \mathrm{C} / 85 \% \mathrm{RH}$ condition.

The resistivity of $\mathrm{Cu}-\mathrm{Ag}$ nanowires depending on different molar ratios of silver and copper was compared with copper nanowires. The resistivity of copper nanowires was dramatically increased within few hours and then, copper nanowires became nonconductive, while the resistivity of $\mathrm{Cu}-\mathrm{Ag}$ nanowires indicated significantly lower resistivity than copper nanowire and were revealed the stability over $24 \mathrm{~h}$. However, as a molar ratio of silver was increased, the resistivity was not observe tendency to decrease (Cruz et al. [2018]).

Since $\mathrm{Au}$ and $\mathrm{Pt}$ have higher resistivity than copper, $\mathrm{Cu}-\mathrm{Au}$ and $\mathrm{Cu}-\mathrm{Pt}$ nanowires exhibit a higher resistivity than copper nanowires (Stewart et al. [2015]). However, the $\mathrm{Au}$ and $\mathrm{Pt}$ as shell metals have been proven the stability of core-shell nanowires (Niu et al. [2017]; Chen et al. [2014]). 


\subsection{Objectives}

The objective of this study is to optimize synthesis of copper nanowire for improvement the quality based on a solution-based method under practical condition. In order to determine and evaluate the quality including yields and dimensions of copper nanowires, the effect of concentration of $\mathrm{N}_{2} \mathrm{H}_{4}, \mathrm{EDA}, \mathrm{NaOH}$, and copper precursor, and various synthesis temperatures are compared and analyzed. In addition, this study is to demonstrate the fabrication of core-shell structure nanowires, which are covered with silver on the surface of copper nanowires, using organic compound A. Consequently, this study proposes the optimization of synthesis of copper nanowire and a new facile method for fabrication of core-shell structure nanowire.

In the following chapters of this study, Chapter 2 shows selection materials and experimental procedure first, and then, the results of copper nanowires synthesized under different amount of chemicals are characterized and discussed. Chapter 3 shows a new facile method for fabrication of $\mathrm{Cu}-\mathrm{Ag}$ nanowire and the elements of $\mathrm{Cu}-\mathrm{Ag}$ nanowire are verified. 


\section{Chapter 2}

\section{Synthesis of Copper Nanowire}

\subsection{Materials}

In order to synthesize copper nanowires by using the solution-based method, some of chemicals can be used to play indispensable roles of reagent, copper precursor, capping agent, and reducing agent. The quality of copper nanowire can be determined depending on the roles and concentrations of used chemicals.

Sodium hydroxide $(\mathrm{NaOH})$ is employed as the reagent at the beginning step of synthesis of copper nanowire. $\mathrm{NaOH}$ is usually utilized to prevent copper ions from generating copper hydroxide $\left(\mathrm{Cu}(\mathrm{OH})_{2}\right)$ precipitates (Wen et al. [2005]). Copper chloride $\left(\mathrm{CuCl}_{2}\right)$ is utilized as the copper precursor. Common copper precursors rather than copper organometallic are suitable for the solution-based method. Ethylenediamine (EDA, $\mathrm{C}_{2} \mathrm{H}_{8} \mathrm{~N}_{2}, 99.5 \%$ ) is used as capping agent for preventing copper seeds from being aggregated. Hydrazine $\left(\mathrm{N}_{2} \mathrm{H}_{4}, 35 \mathrm{wt} \%\right)$ is consumed as reducing agent, which is generally responsible for performing reduction copper ions to copper atoms (Jin et al. [2011]). Deionized water $\left(\mathrm{DI} \mathrm{H}_{2} \mathrm{O}\right)$ is used as solvent to dissolve $\mathrm{NaOH}$ 
and $\mathrm{CuCl}_{2}$, and to dilute $\mathrm{N}_{2} \mathrm{H}_{4}$.

\subsection{Experimental Procedure}

In this study, as shown in Figure 2.1, solution-based method is employed to synthesize of copper nanowire with various amount of chemicals. All of experiment are carried out under $300 \mathrm{rpm}$ magnetic stirring to reach homogeneous condition. In addition, to prevent the solution temperature from increasing or decreasing, water-bath is used and kept at constant temperature $\left(40{ }^{\circ} \mathrm{C}, 50{ }^{\circ} \mathrm{C}, 60{ }^{\circ} \mathrm{C}, 70{ }^{\circ} \mathrm{C}, 80{ }^{\circ} \mathrm{C}\right.$, and $\left.90{ }^{\circ} \mathrm{C}\right)$ during 2 hours reaction time.

First, $\mathrm{NaOH}(0.967 \mathrm{~g}, 1.024 \mathrm{~g}, 1.44 \mathrm{~g}, 1.85 \mathrm{~g}, 2.56 \mathrm{~g}$, and $2.94 \mathrm{~g})$ is dissolved in 5 $\mathrm{ml}$ of $\mathrm{DI} \mathrm{H}_{2} \mathrm{O}$ in water-bath. After 10 mins, once $\mathrm{NaOH}$ is completely dissolved with colorless, EDA $(15 \mu \mathrm{l}, 30 \mu \mathrm{l}, 50 \mu \mathrm{l}$, and $60 \mu \mathrm{l})$ is then added in $\mathrm{NaOH}$ solution and the solution is still colorless. After 2 mins, $\mathrm{CuCl}_{2}(4.6 \mathrm{mg}$ and $10 \mathrm{mg})$ dissolved in 2 $\mathrm{ml}$ of $\mathrm{DI} \mathrm{H}_{2} \mathrm{O}$ is added and stirred for 10 mins. As soon as adding of $\mathrm{CuCl}_{2}$ aqueous solution, the solution color is showed light blue then turned into dark blue after 10 mins. $\mathrm{CuCl}_{2}$ can be easily aggregated in solution, however, EDA added first can prevent it from aggregating. The following chemical reaction STEP 1. is occurred:

STEP 1. $2 \mathrm{NaOH}(\mathrm{aq})+\mathrm{CuCl}_{2} \rightarrow \mathrm{Cu}(\mathrm{OH})_{2}+2 \mathrm{NaCl}$

As shown in chemical reaction STEP 1., copper hydroxide $\mathrm{Cu}(\mathrm{OH})_{2}$ are formed and at this time, EDA surrounds theirs surface to make it stabilization without aggregation. Prior to $\mathrm{N}_{2} H_{4}$ being used, $\mathrm{N}_{2} H_{4}(0.3 \mathrm{ml}$ and $1 \mathrm{ml})$ is diluted in $3 \mathrm{ml}$ of DI 


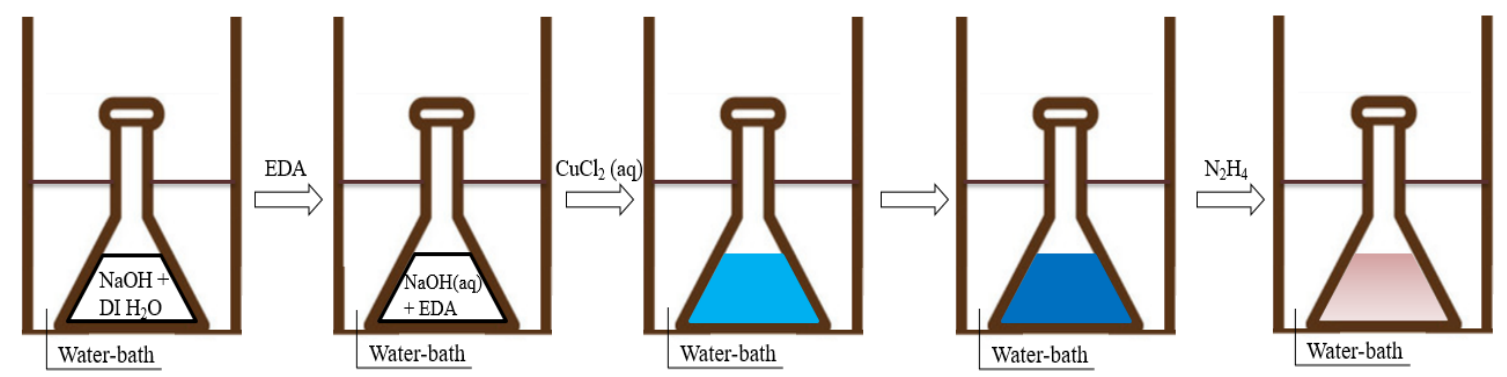

Figure 2.1: Synthesis process of copper nanowire

DI $\mathrm{H}_{2} \mathrm{O}$. Eventually, diluted $N_{2} H_{4}(15 \mu \mathrm{l}, 30 \mu \mathrm{l}, 240 \mu \mathrm{l})$ is added into total solution. The following chemical reaction STEP 2. and STEP 3. are taken place:

STEP 2. $\mathrm{Cu}(\mathrm{OH})_{2}+\mathrm{N}_{2} \mathrm{H}_{4} \rightarrow 2 \mathrm{Cu}_{2} \mathrm{O}+\mathrm{N}_{2}+\mathrm{H}_{2} \mathrm{O}$

STEP 3. $2 \mathrm{Cu}_{2} \mathrm{O}+\mathrm{N}_{2} \mathrm{H}_{4} \rightarrow 4 \mathrm{Cu}+2 \mathrm{H}_{2} \mathrm{O}+\mathrm{N}_{2}$

As shown in chemical reaction STEP 2. and STEP 3., $\mathrm{Cu}(\mathrm{OH})_{2}$ are reduced to copper oxide $\left(\mathrm{Cu}_{2} \mathrm{O}\right)$ particles by reducing copper ions because of addition of reducing agent. With heating continuously provided by water-bath in presence of diluted $\mathrm{N}_{2} \mathrm{H}_{4}$, $\mathrm{Cu}_{2} \mathrm{O}$ are further reduced to copper atom, which will grow up copper nanowire. The color of final solution is changed from dark blue to reddish brown during 2hours reaction time. Finally, the solution is washed with methanol to eliminate chemical impurity. The conditions of chemicals are summarized in Table 2.1. 
Table 2.1: Experimental conditions of chemicals

\begin{tabular}{|c|c|c|c|c|c|c|c|c|c|c|c|c|c|}
\hline \multicolumn{4}{|c|}{$\mathrm{NaOH}$ Solution } & \multicolumn{2}{|c|}{ EDA } & \multicolumn{4}{|c|}{$\mathrm{CuCl}_{2}$ Solution } & \multicolumn{4}{|c|}{$\mathrm{N}_{2} H_{4}$ Solution } \\
\hline No. & $\begin{array}{c}\mathrm{NaOH} \\
(\mathrm{g})\end{array}$ & $\begin{array}{c}\mathrm{DI} \\
\mathrm{H}_{2} \mathrm{O} \\
(\mathrm{ml})\end{array}$ & $\begin{array}{c}\text { Molar } \\
(\mathrm{M})\end{array}$ & No. & $(\mu \mathrm{l})$ & No. & $\begin{array}{c}\mathrm{CuCl}_{2} \\
(\mathrm{mg})\end{array}$ & $\begin{array}{c}\text { DI } \\
\mathrm{H}_{2} \mathrm{O} \\
(\mathrm{ml})\end{array}$ & $\begin{array}{l}\text { Molar } \\
(\mathrm{mM})\end{array}$ & No. & $\begin{array}{c}\mathrm{N}_{2} H_{4} \\
(\mathrm{ml})\end{array}$ & $\begin{array}{c}\mathrm{DI} \\
\mathrm{H}_{2} \mathrm{O} \\
(\mathrm{ml})\end{array}$ & $\begin{array}{l}\text { Molar } \\
(\mathrm{mM})\end{array}$ \\
\hline S1 & 0.967 & 5 & 4.8 & E1 & 15 & $\mathrm{C} 1$ & 4.6 & 2 & 17.1 & N1 & 0.3 & 3 & 1.71 \\
\hline $\mathrm{S} 2$ & 1.024 & 5 & 5 & E2 & 30 & $\mathrm{C} 2$ & 10 & 2 & 37.2 & N2 & 1 & 3 & 5.7 \\
\hline S3 & 1.44 & 5 & 7 & E3 & 50 & - & - & - & - & - & - & - & - \\
\hline $\mathrm{S} 4$ & 1.85 & 5 & 9 & E4 & 60 & - & - & - & - & - & - & - & - \\
\hline S5 & 2.56 & 5 & 12 & - & - & - & - & - & - & - & - & - & - \\
\hline S6 & 2.94 & 5 & 14.7 & - & - & - & - & - & - & - & - & - & - \\
\hline
\end{tabular}




\subsection{Characterization}

The morphology and dimensions of synthesized copper nanowires are observed and measured by using Scanning Electron Microscopy and Transmission Electron Microscopy.

\section{Scanning Electron Microscopy}

The Scanning Electron Microscopy (SEM; FEI Helios 400) is one of the popular instruments to analyze sample surface or bulk material. The SEM technique is effective and simple to interpret sample with three-dimensional images. High electron voltage $(1-40 \mathrm{kV})$ in the SEM is used to generate signals, such as secondary electrons and backscattered electrons. They are generally signals used for imaging. Secondary electrons are very useful for analyzing topography and morphology on sample and backscattered electrons are very helpful for imaging composition contrast with emitted deeper depths rather than secondary electrons. SEM image is obtained without optical transformation and virtual optical images are not provided.

For sample preparation, fine power samples are required to be placed hard on sample holder to prevent them from being damaged in the SEM chamber. On the other hand, non-conductive samples have to be coated with thin conductive layer, such as gold and palladium, and are placed on conductive holder.

In this study, samples of liquid and solid state are prepared by washing with 
methanol to remove chemical impurities and then, placed on the sample holder, which is attached copper tape. Afterwards, the holder on which the sample is placed is dried in a vacuum dryer for SEM characterization.

\section{Transmission Electron Microscopy}

The Transmission Electron Microscopy (TEM; FEI Tecnai F-20) is widely used instrument for allowing visualization and analysis of nanoscale sample. The TEM technique is very valuable for imaging by illuminating the sample with electron beam in a high vacuum column. TEM used in this study operates high energy electrons than SEM up to $200 \mathrm{kV}$ accelerating voltage and is loaded Energy-dispersive X-ray Spectroscopy (EDX). The electron beams in the TEM column pass through a sample and then, electrons are scattered. And then, electromagnetic lenses concentrate on scattered electrons. These electrons are gathered below the sample onto a phosphorescent screen. Once inserting of objective lens, the bright field image is formed with direct electron beam and the dark field image is formed with diffracted beam by tilting angle. The Scanning TEM (STEM) mode that uses angular dark field detector is required to obtain atomic resolution images and to analyze chemical composition in the sample working EDX.

In this study, bright field imaging technique is used dominantly and STEM imaging technique is utilized for EDX to analyze sample component included. For sample preparation, 300 mesh copper grid with lacey carbon is employed for TEM character- 
ization. The droplet of sample is dropped onto the grid and then, copper nanowires are suspended on the top of grid after 5 mins. After the aqueous solution dropped on copper grid is filtered to the opposite side of grid and is completely removed. The grid with suspended nanowire is washed with methanol to remove remaining chemical impurities. Finally, the grid is dried in a vacuum dryer.

\subsection{Results}

\section{The Effect of Concentration of $\mathrm{N}_{2} \mathrm{H}_{4}$}

In order to find out the formation of copper nanowires, various concentration of diluted $\mathrm{N}_{2} \mathrm{H}_{4}$ are used as shown in Table 2.2. The concentration of NaOH, EDA, and $\mathrm{CuCl}_{2}$ are kept for this experiment with $\mathrm{S} 1, \mathrm{E} 3$, and $\mathrm{C} 1$, respectively, and the reaction temperature is kept at $60{ }^{\circ} \mathrm{C}$ during 2 hours reaction time.

Table 2.2: Experiment conditions of diluted $\mathrm{N}_{2} \mathrm{H}_{4}$

\begin{tabular}{|c|c|c|c|}
\hline \multicolumn{4}{|c|}{$\mathrm{N}_{2} H_{4}$ Solution (N1) } \\
\hline $\mathrm{N}_{2} H_{4}(\mathrm{ml})$ & $\mathrm{DI} \mathrm{H} \mathrm{H}_{2} \mathrm{O}(\mathrm{ml})$ & Molarity $(\mathrm{mM})$ & Vol. $(\mu \mathrm{l})$ \\
\hline 0.3 & 3 & 1.71 & 15 \\
\hline 0.3 & 3 & 1.71 & 30 \\
\hline 0.3 & 3 & 1.71 & 240 \\
\hline
\end{tabular}

Figures 2.2 to 2.4 show SEM images of synthesized copper nanowires with various concentrations of diluted $\mathrm{N}_{2} H_{4}$. By adding $15 \mu$ of diluted $\mathrm{N}_{2} H_{4}$, copper nanowires with high yield, the length of $4-13 \mu \mathrm{m}$, and the diameter of $250-550 \mathrm{~nm}$ are obtained 

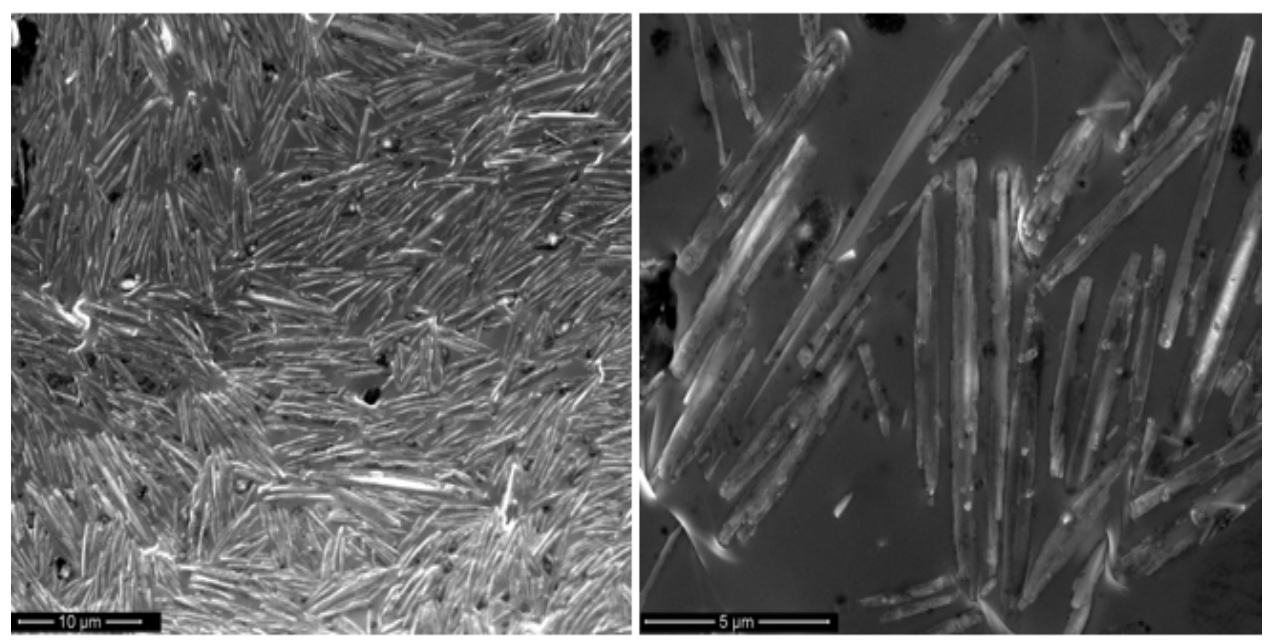

Figure 2.2: SEM images of copper nanowires with $15 \mu \mathrm{l}$ of $\mathrm{N}_{2} H_{4}$

as shown in Figure 2.2, while at $50 \mu \mathrm{l}$ of diluted $\mathrm{N}_{2} H_{4}$, copper nanowires are produced low yield compared with $15 \mu$ l of diluted $\mathrm{N}_{2} H_{4}$. In this case, the diameter and length display 4 - $15 \mu \mathrm{m}$ and 450 - $750 \mathrm{~nm}$, respectively, as shown inthe Figure 2.3. In terms of dimensions of synthesized copper nanowires, there are no significantly different between $15 \mu \mathrm{l}$ and $30 \mu \mathrm{l}$ of diluted $\mathrm{N}_{2} \mathrm{H}_{4}$, however, the yield of copper nanowires is demonstrated a remarkable difference. By adding $240 \mu \mathrm{l}$ of diluted $\mathrm{N}_{2} H_{4}$, copper nanoparticles, which have the diameter of $800 \mathrm{~nm}$, are observed dominantly without any copper nanowires and the agglomeration of copper nanoparticles as shown in Figure 2.4. 


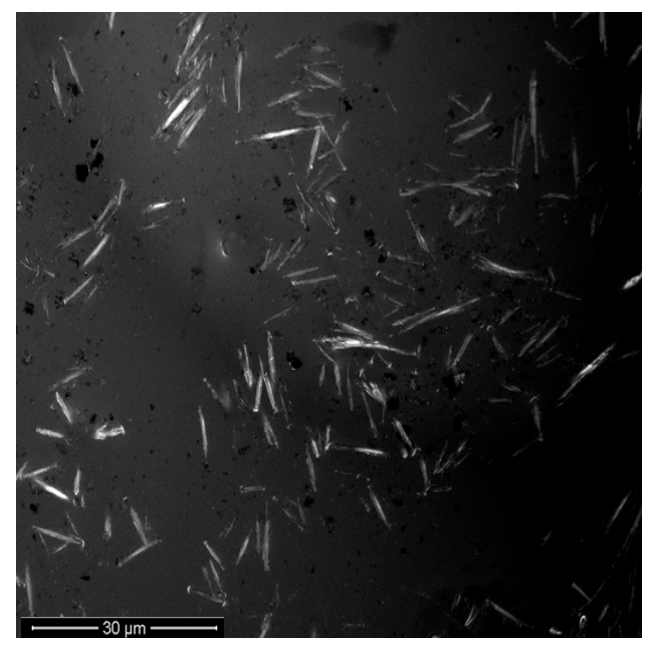

Figure 2.3: SEM image of copper nanowires with $30 \mu \mathrm{l}$ of $\mathrm{N}_{2} H_{4}$

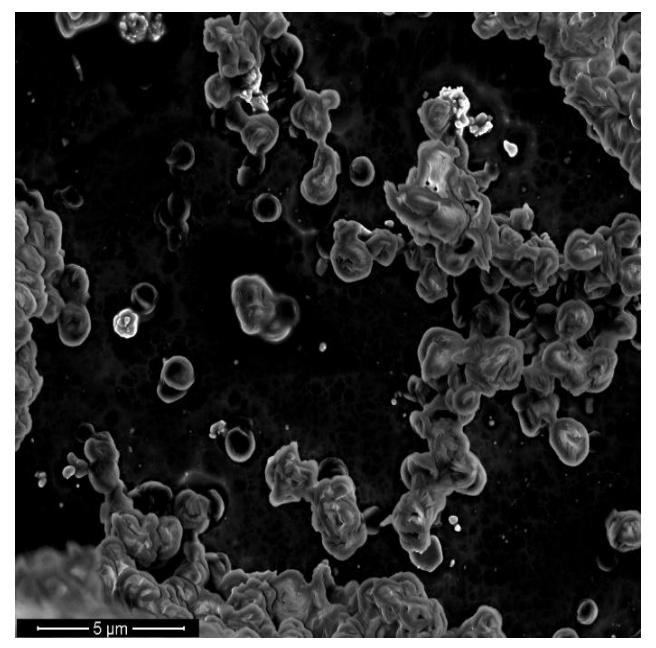

Figure 2.4: SEM image of copper nanoparticles with $240 \mu \mathrm{l}$ of $\mathrm{N}_{2} H_{4}$ 


\section{The Effect of Temperature on Morphology of Copper Nanowire}

To find out how the morphology of copper nanowires varies depending on temperature, synthesis of copper nanowires implements at various temperature $\left(40{ }^{\circ} \mathrm{C}, 50{ }^{\circ} \mathrm{C}, 60\right.$ ${ }^{\circ} \mathrm{C}, 70{ }^{\circ} \mathrm{C}, 80{ }^{\circ} \mathrm{C}$, and $90{ }^{\circ} \mathrm{C}$ ). The concentration of $\mathrm{NaOH}, \mathrm{EDA}, \mathrm{CuCl}_{2}$, and $\mathrm{N}_{2} \mathrm{H}_{4}$ are kept with S6, E2, C1, and $15 \mu \mathrm{l}$ of N2, respectively.

Figures 2.5 to 2.10 show TEM images of synthesized copper nanowires at various processing temperatures. Figure 2.5 shows that synthesized copper nanowires at 40 ${ }^{\circ} \mathrm{C}$ have the length of longer than $3.5 \mu \mathrm{m}$ and the diameter $130-250 \mathrm{~nm}$. At 40 ${ }^{\circ} \mathrm{C}$, the surface of copper nanowires is not smoothly synthesized with showing dent area. In addition, the aggregation of copper seeds is displayed and it makes copper seeds difficult to grow to copper nanowires. Synthesized copper nanowires at $50{ }^{\circ} \mathrm{C}$ show the length of longer than $5 \mu \mathrm{m}$ and the diameter of $130-280 \mathrm{~nm}$. As shown in Figure 2.6, and the aggregation of copper seeds are improved compared to $40{ }^{\circ} \mathrm{C}$. In Figure 2.7, copper nanowires are indicated with the length of longer than $8 \mu \mathrm{m}$ and the diameter of $200-310 \mathrm{~nm}$, and the aggregation of copper seeds is not represented unlike copper nanowires synthesized at $40{ }^{\circ} \mathrm{C}$ and $50{ }^{\circ} \mathrm{C}$. Figure 2.8 shows strongly the smooth surface of copper nanowires with the length of longer than $5 \mu \mathrm{m}$ and the diameter of 210 - $260 \mathrm{~nm}$. As shown in Figure 2.9, synthesized copper nanowires at $80{ }^{\circ} \mathrm{C}$ reveal the length of longer than $6 \mu \mathrm{m}$ and the diameter of $120-280 \mathrm{~nm}$. At this time, the thinner diameter of copper nanowires is obatined at $80^{\circ} \mathrm{C}$. However, broken 
area is revealed at the end of copper nanowire. At $90{ }^{\circ} \mathrm{C}$, not only copper nanowires also copper seeds are demonstrated oxidation of them as shown in Figure 2.10. This is because copper is essentially an oxidizable metal material and the oxidation of it is accelerated by relatively high temperature. 


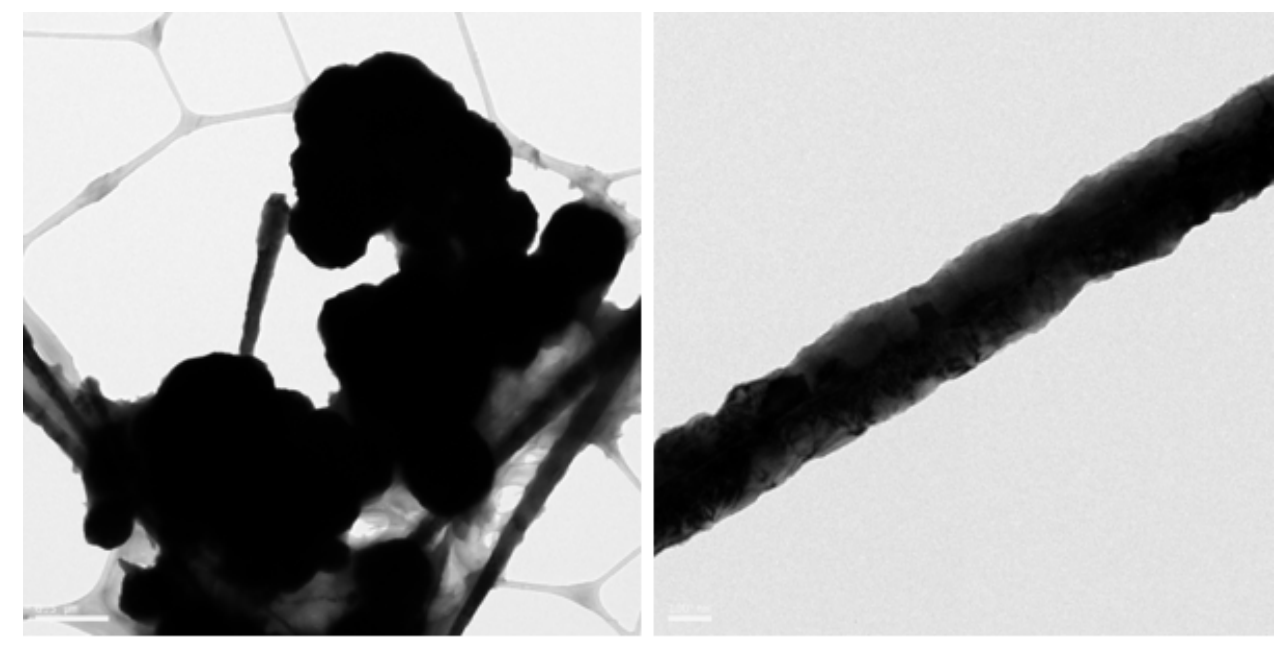

Figure 2.5: TEM images of copper nanowires at $40{ }^{\circ} \mathrm{C}$

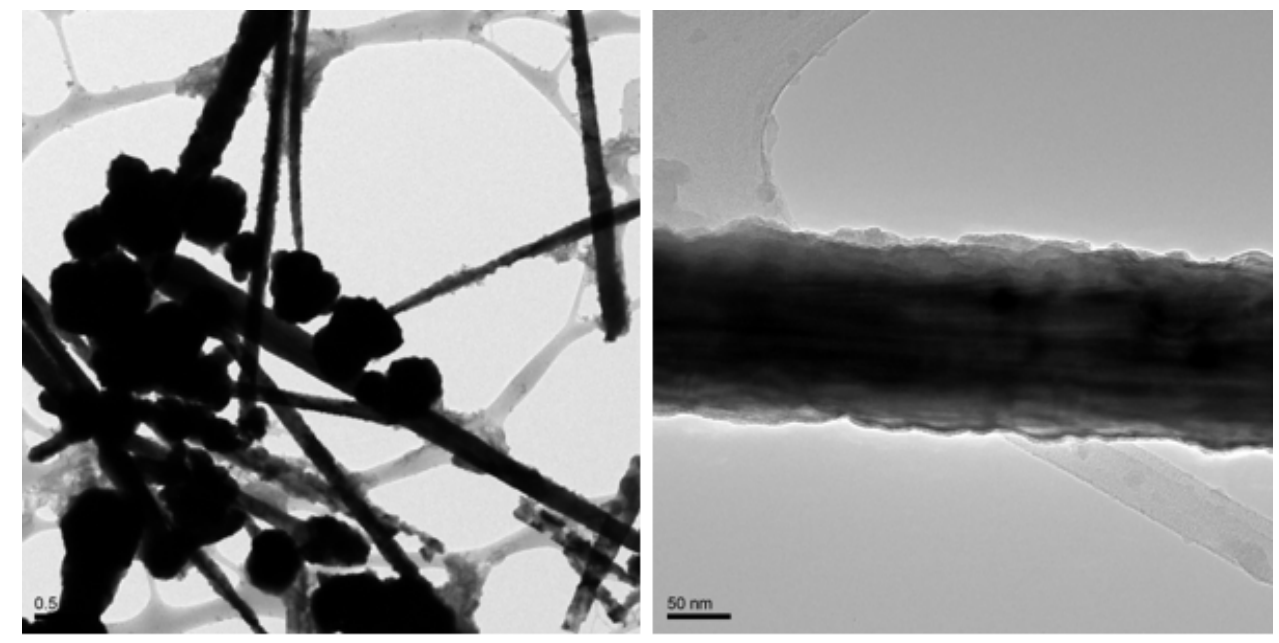

Figure 2.6: TEM images of copper nanowires at $50{ }^{\circ} \mathrm{C}$ 


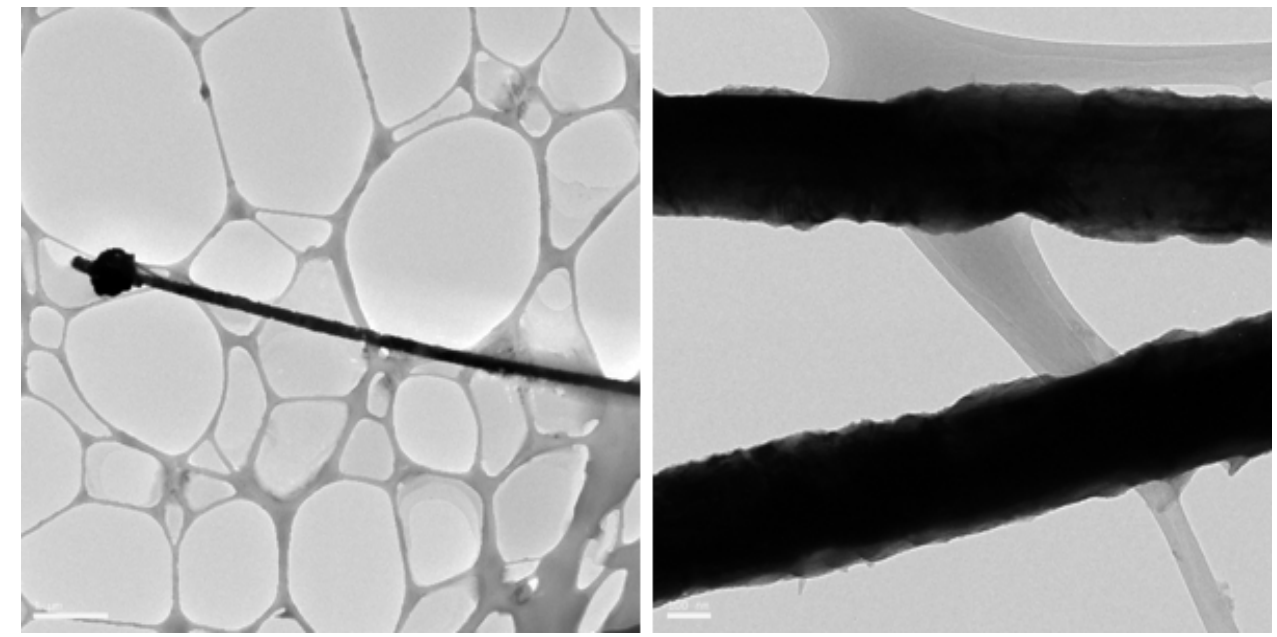

Figure 2.7: TEM images of copper nanowires at $60^{\circ} \mathrm{C}$

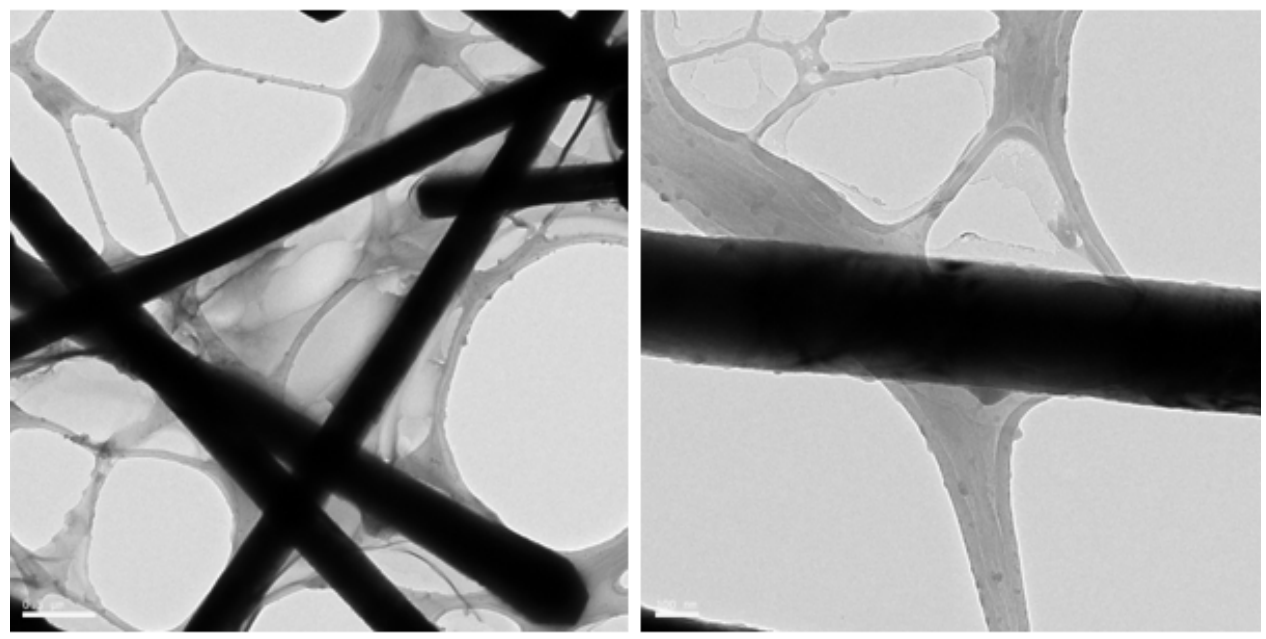

Figure 2.8: TEM images of copper nanowires at $70{ }^{\circ} \mathrm{C}$ 


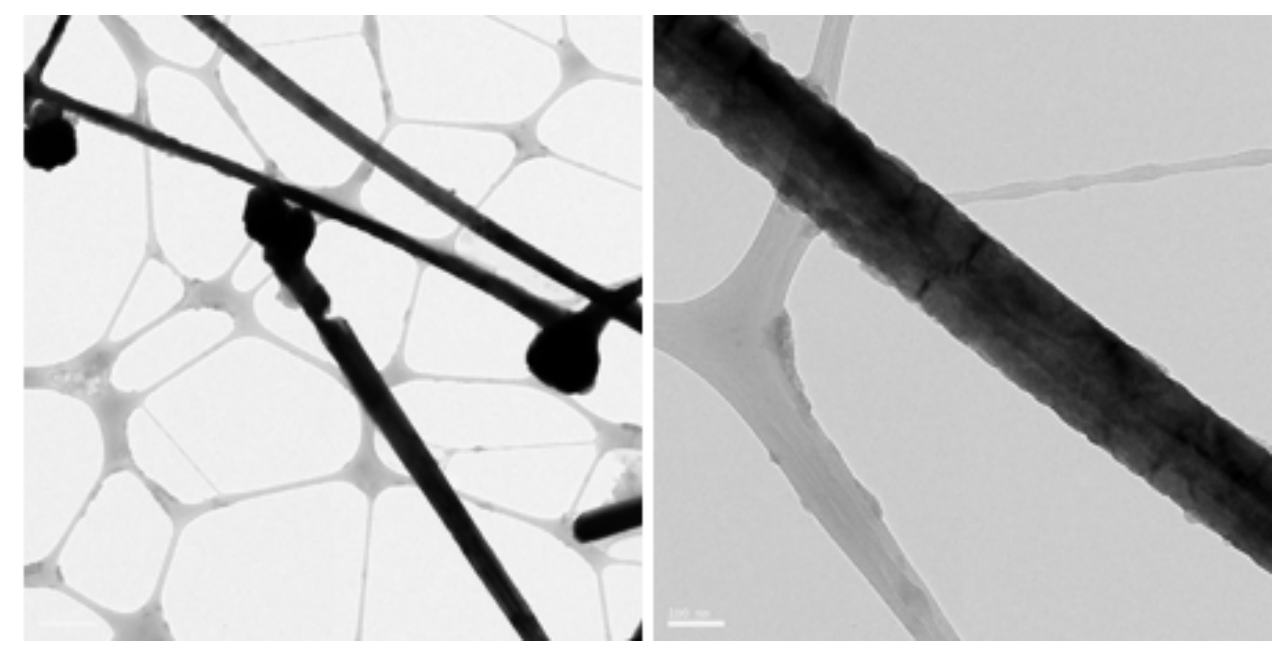

Figure 2.9: TEM images of copper nanowires at $80{ }^{\circ} \mathrm{C}$
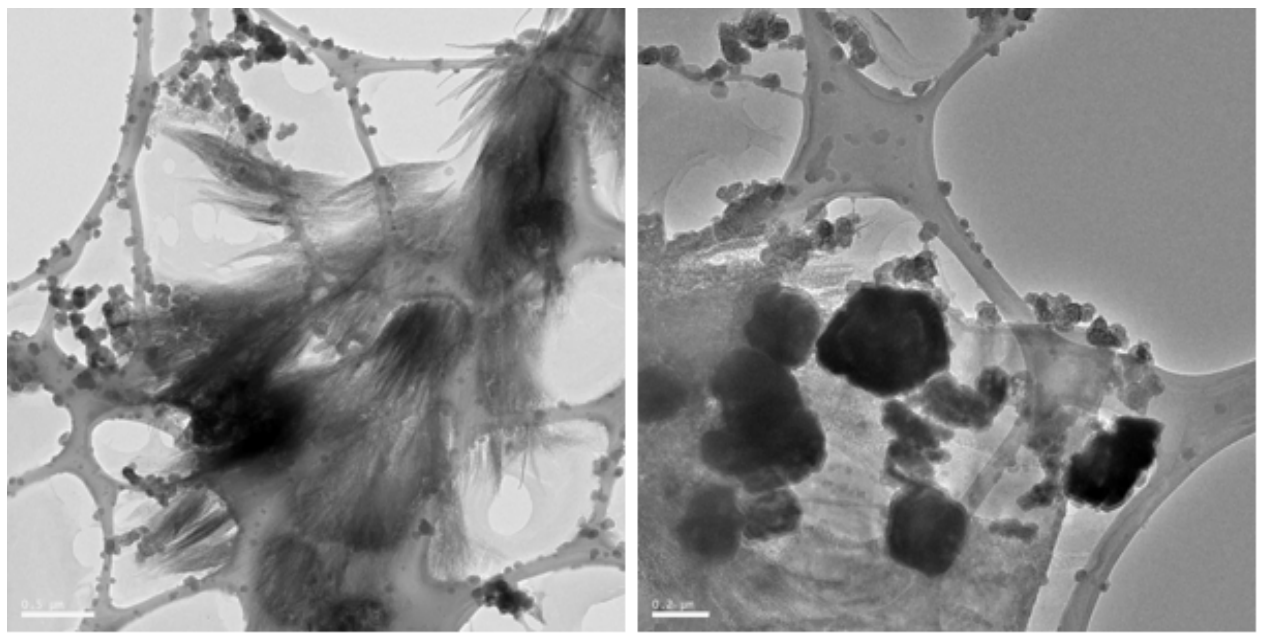

Figure 2.10: TEM images of copper products at $90{ }^{\circ} \mathrm{C}$ 


\section{The Effect of Concentration of EDA}

Copper nanowires are synthesized in the presence of different amount of EDA to understand the effect of EDA. $15 \mu \mathrm{l}, 50 \mu \mathrm{l}$, and $60 \mu \mathrm{l}$ of EDA are added to alter condition. The concentration of $\mathrm{NaOH}, \mathrm{CuCl}_{2}$, and $\mathrm{N}_{2} \mathrm{H}_{4}$ are maintained with $\mathrm{S} 6$, $\mathrm{C} 1$, and $15 \mu \mathrm{l}$ of $\mathrm{N} 2$, respectively, and the reaction temperature is kept at $70{ }^{\circ} \mathrm{C}$ for this experiment.

Figures 2.11 to 2.13 indicate TEM images of synthesized copper nanowires by using different amount of EDA. When $15 \mu \mathrm{l}$ of EDA is added, a few copper seeds are not grown into copper nanowires, and tapered copper nanowires are observed as shown in Figure 2.11. In addition, copper nanowires are observed with the length and diameter of longer than $4 \mu \mathrm{m}$ and 150 - $220 \mathrm{~nm}$, respectively. As the amount of EDA increases to $50 \mu \mathrm{l}$, the formation of copper nanowires is remarkably transformed as shown in Figure 2.12. The tapered copper nanowires are dominated with the length of longer than $2 \mu \mathrm{m}$ and the diameter of $210-270 \mathrm{~nm}$. However, copper seeds are not observed unlike $15 \mu \mathrm{l}$ of EDA. Figure 2.13 displays copper nanowires produced with further increasing amount of EDA to $60 \mu \mathrm{l}$ and the length and the diameter are revealed longer than $6 \mu \mathrm{m}$ and $130-170 \mathrm{~nm}$, respectively. The dimensions of copper nanowires are improved with a little bit longer length and thinner diameter compared with the addition of $15 \mu \mathrm{l}$ and $50 \mu \mathrm{l}$ of EDA, however, copper nanoparticles are observed not only their own but also on the surface of copper nanowires. 

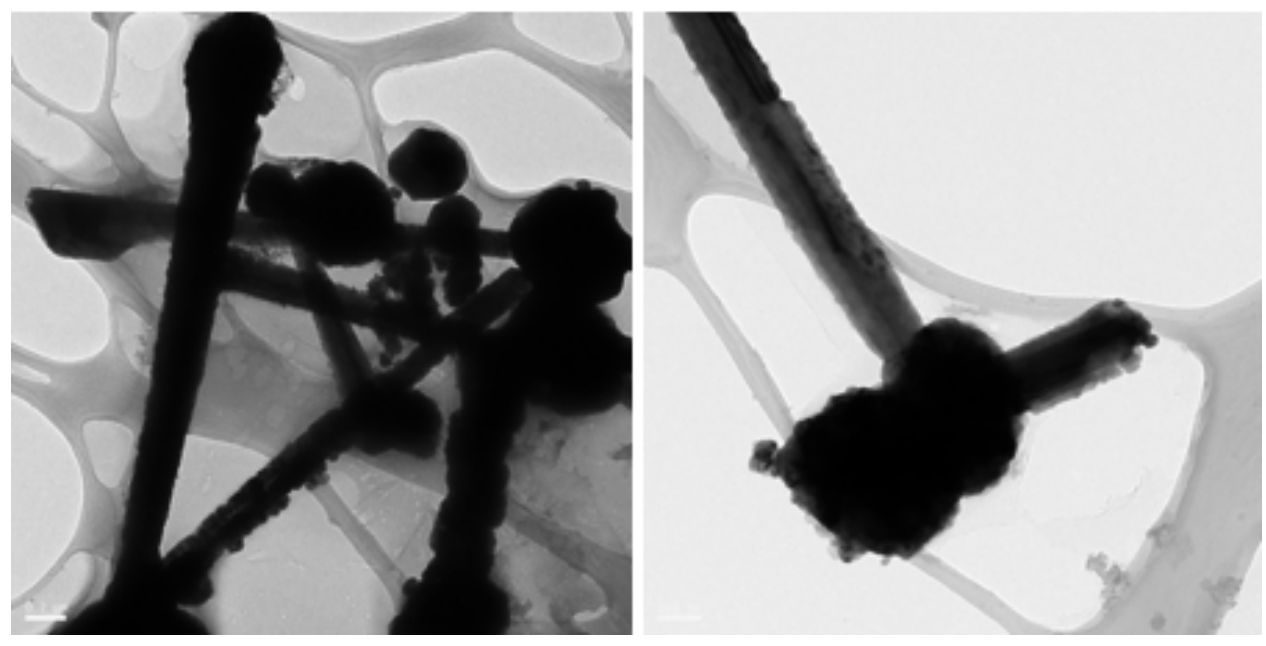

Figure 2.11: TEM images of copper nanowires with $15 \mu \mathrm{l}$ of EDA
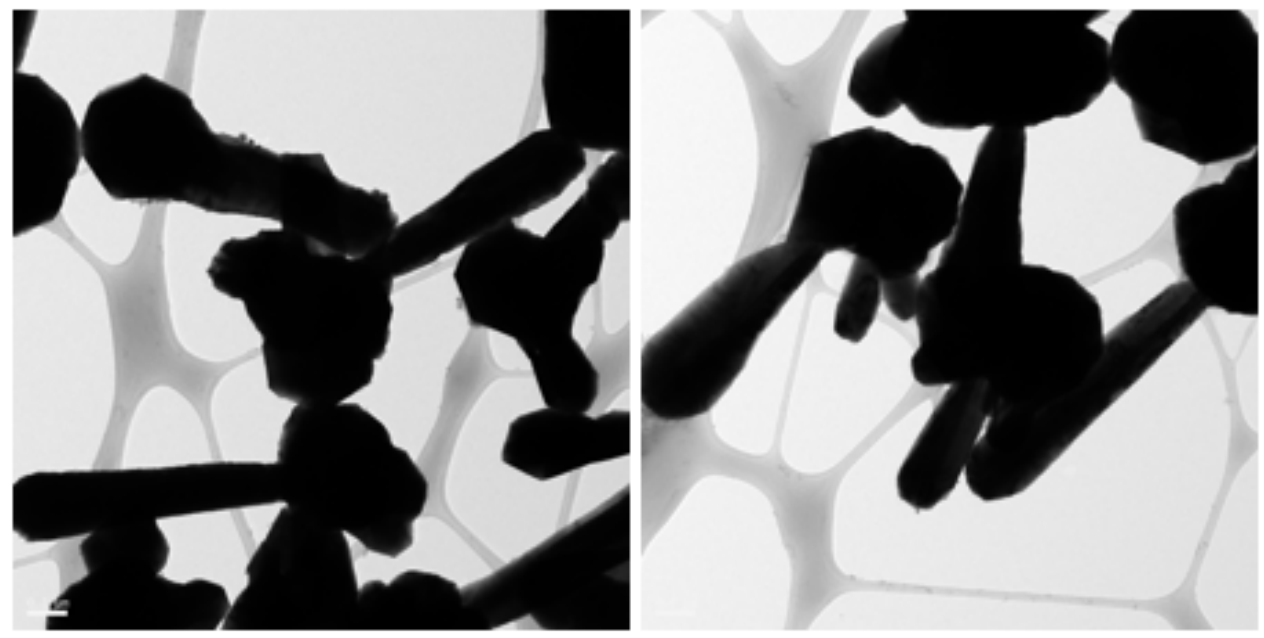

Figure 2.12: TEM images of copper nanowires $50 \mu \mathrm{l}$ of EDA 

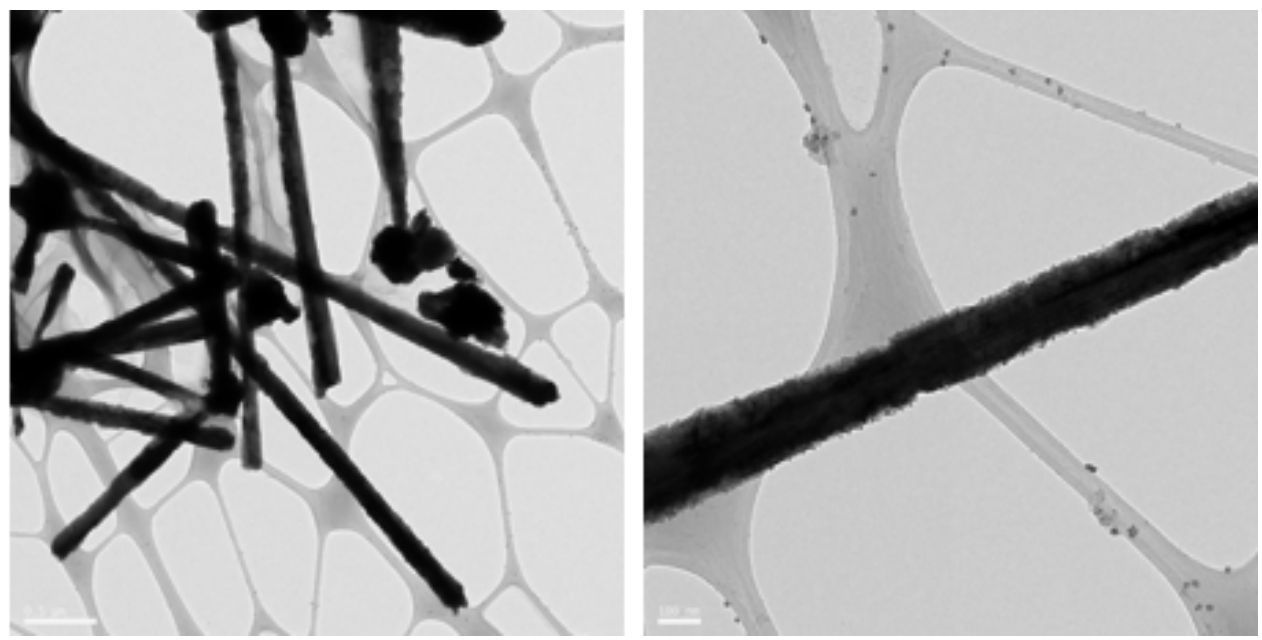

Figure 2.13: TEM images of copper nanowires $60 \mu \mathrm{l}$ of EDA

\section{The Effect of Concentration of $\mathrm{NaOH}$}

In this study, the experiments are performed with various amounts of $\mathrm{NaOH}(5 \mathrm{M}, 7$ M, $9 \mathrm{M}$, and $12 \mathrm{M}$ ) to find out the formation of copper nanowires. The concentration of EDA, $\mathrm{CuCl}_{2}$, and $\mathrm{N}_{2} \mathrm{H}_{4}$ are maintained $\mathrm{E} 3, \mathrm{C} 1$, and $15 \mu \mathrm{l}$ of $\mathrm{N} 2$, respectively, and the reaction temperature is kept at $70{ }^{\circ} \mathrm{C}$. This experiment condition for the concentration of $\mathrm{NaOH}$ is summarized as shown in Table 2.3.

Table 2.3: Experiment conditions for the effect of concentration of $\mathrm{NaOH}$

\begin{tabular}{|c|c|c|}
\hline \multicolumn{3}{|c|}{$\mathrm{NaOH}$ Solution } \\
\hline $\mathrm{NaOH}(\mathrm{g})$ & DI $\mathrm{H}_{2} \mathrm{O}(\mathrm{ml})$ & Molarity $(\mathrm{M})$ \\
\hline 1.024 & 5 & 5 \\
\hline 1.44 & 5 & 7 \\
\hline 1.85 & 5 & 9 \\
\hline 2.56 & 5 & 12 \\
\hline
\end{tabular}


Figures 2.14 to 2.16 and 2.18 show TEM images of synthesized copper nanowires under different molarity of $\mathrm{NaOH}$. As shown in Figure 2.14, copper nanowires grown under $5 \mathrm{M}$ of $\mathrm{NaOH}$ solution have a length of $3 \mu \mathrm{m}$ and the diameter of $130-250$ nm. In addition, the morphology of copper nanowires displays almost similar compared with Figure 2.12, which shows synthesized copper nanowires under $14.7 \mathrm{M}$ of $\mathrm{NaOH}$ solution (S6). Figure 2.15 shows synthesized copper nanowires under $7 \mathrm{M}$ of $\mathrm{NaOH}$ solution. In this condition, the dimensions of copper nanowires are noticeably developed having the length of longer than $12 \mu \mathrm{m}$ and the diameter of $80-160 \mathrm{~nm}$ compared to previous synthesized copper nanowires. However, the large difference in the diameter of copper nanowires and some of the aggregation of copper seeds are observed. As shown in Figure 2.16, the ultra-long and -thin copper nanowires with the length of longer than $18 \mu \mathrm{m}$ and the diameter of $25-45 \mathrm{~nm}$ are observed under 9 $\mathrm{M}$ of $\mathrm{NaOH}$ solution. Interestingly, copper nanowires are begun to float on the top of solution because of high-density of solution. Moreover, with $9 \mathrm{M}$ of $\mathrm{NaOH}$ solution, the ultra-high yield of copper nanowires is obtained as shown in Figure 2.17 without centrifugation process. Figure 2.18 shows copper nanowires synthesized under $12 \mathrm{M}$ of $\mathrm{NaOH}$ solution. The length and the diameter of copper nanowires are longer than $12 \mu \mathrm{m}$ and $100-500 \mathrm{~nm}$, respectively. In addition, the aggregation of copper seeds is shown again and the large difference in the diameter of copper nanowire can be easily visualized in Figure 2.18. 


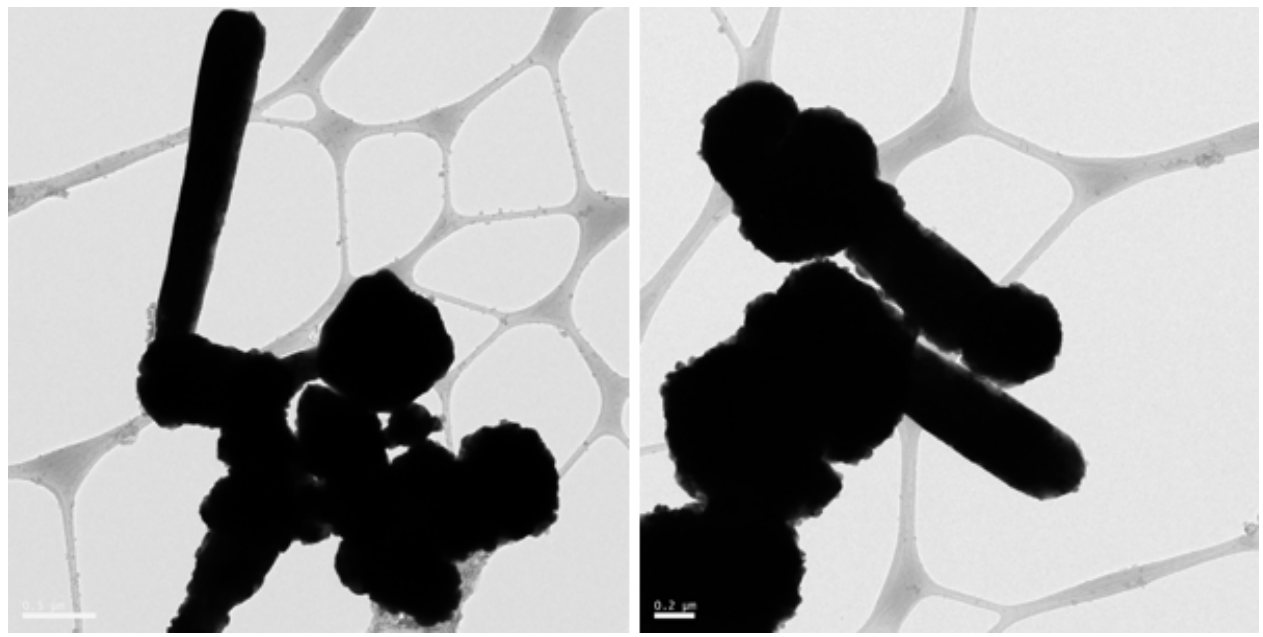

Figure 2.14: TEM images of copper nanowires with $5 \mathrm{M}$ of $\mathrm{NaOH}$

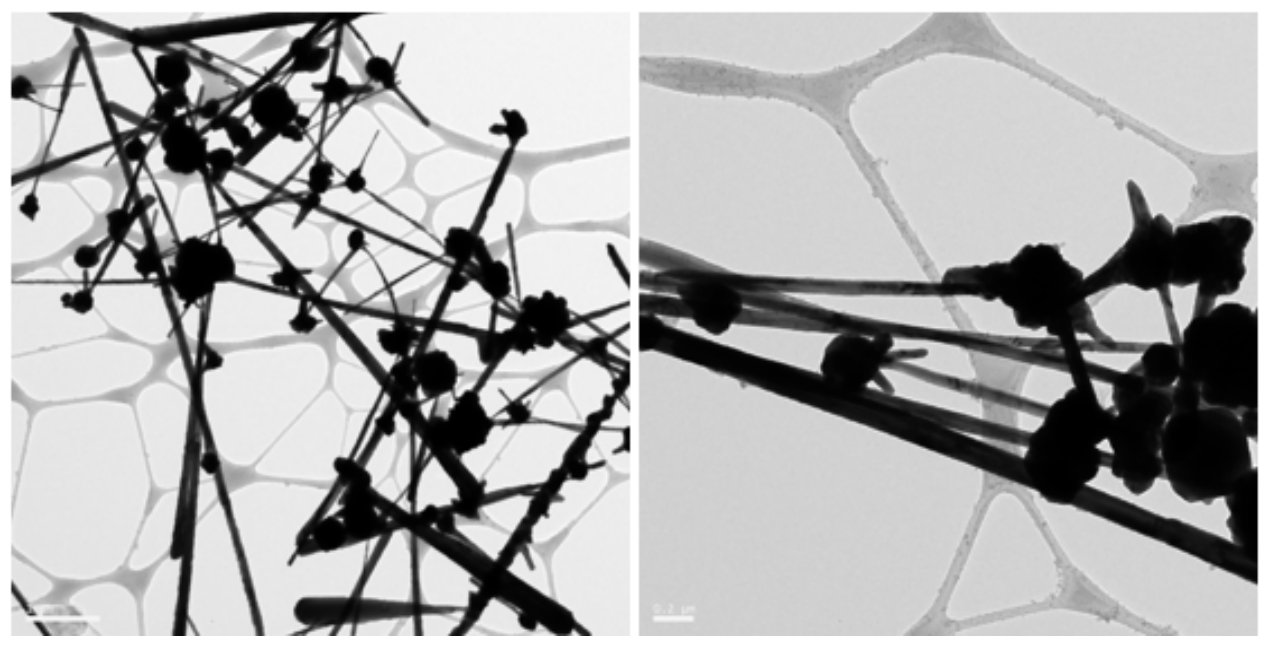

Figure 2.15: TEM images of copper nanowires with $7 \mathrm{M}$ of $\mathrm{NaOH}$ 

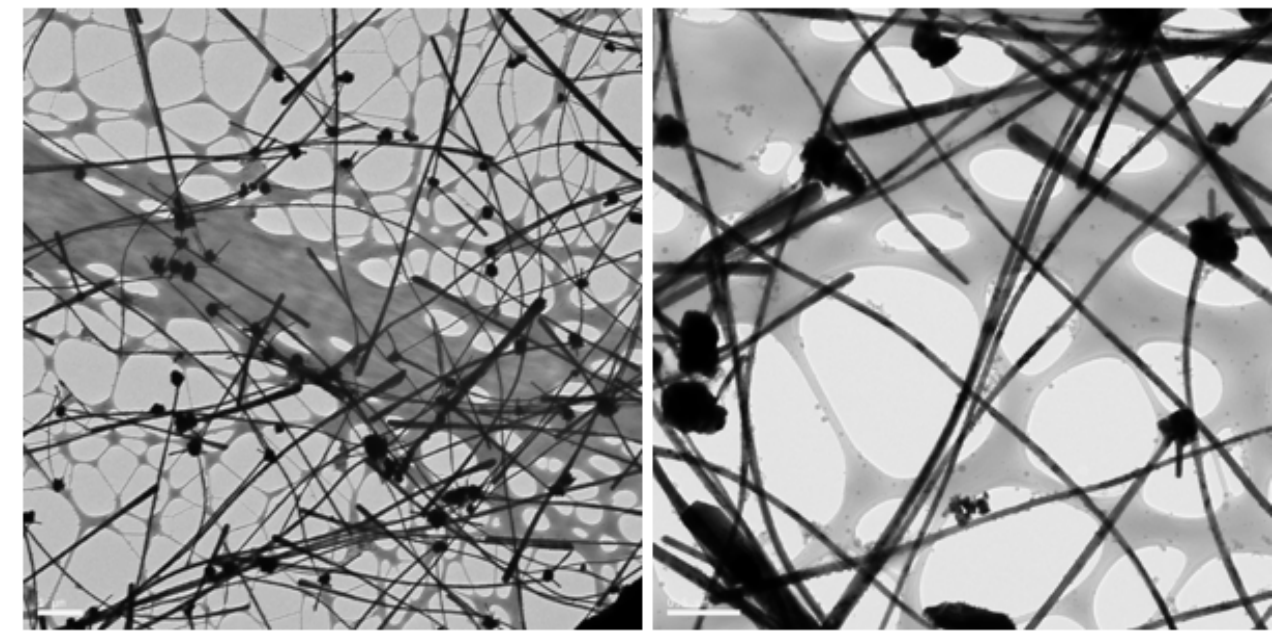

Figure 2.16: TEM images of copper nanowires with $9 \mathrm{M}$ of $\mathrm{NaOH}$
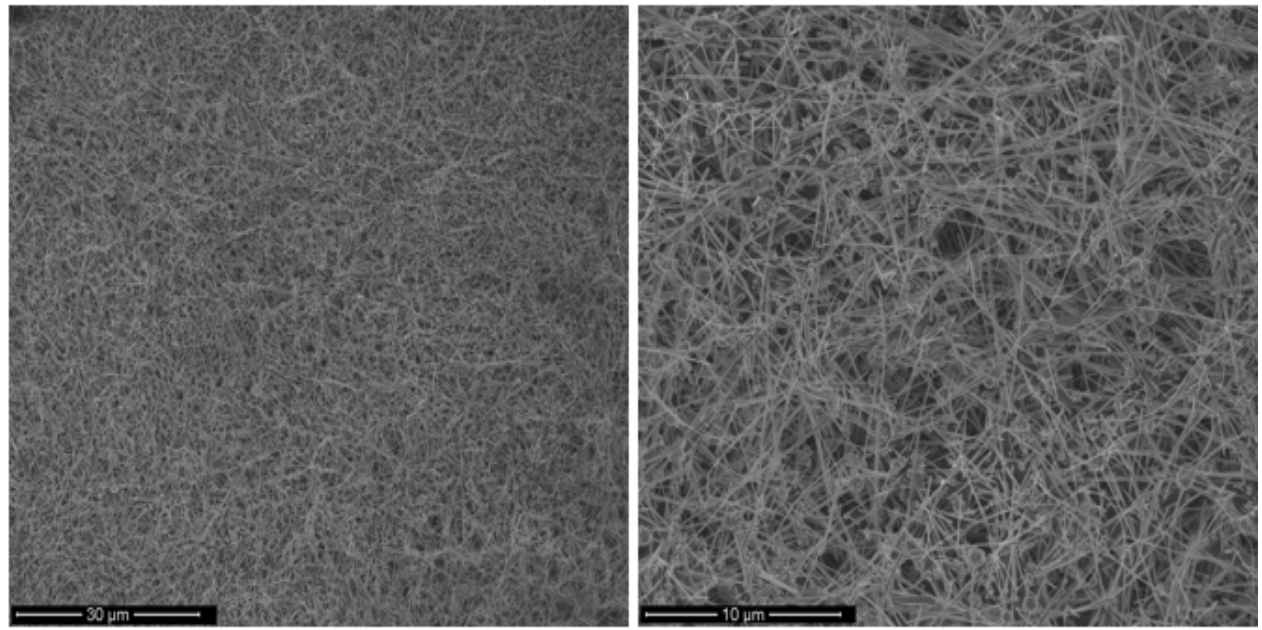

Figure 2.17: SEM Images of Copper Nanowires with $9 \mathrm{M}$ of $\mathrm{NaOH}$ 

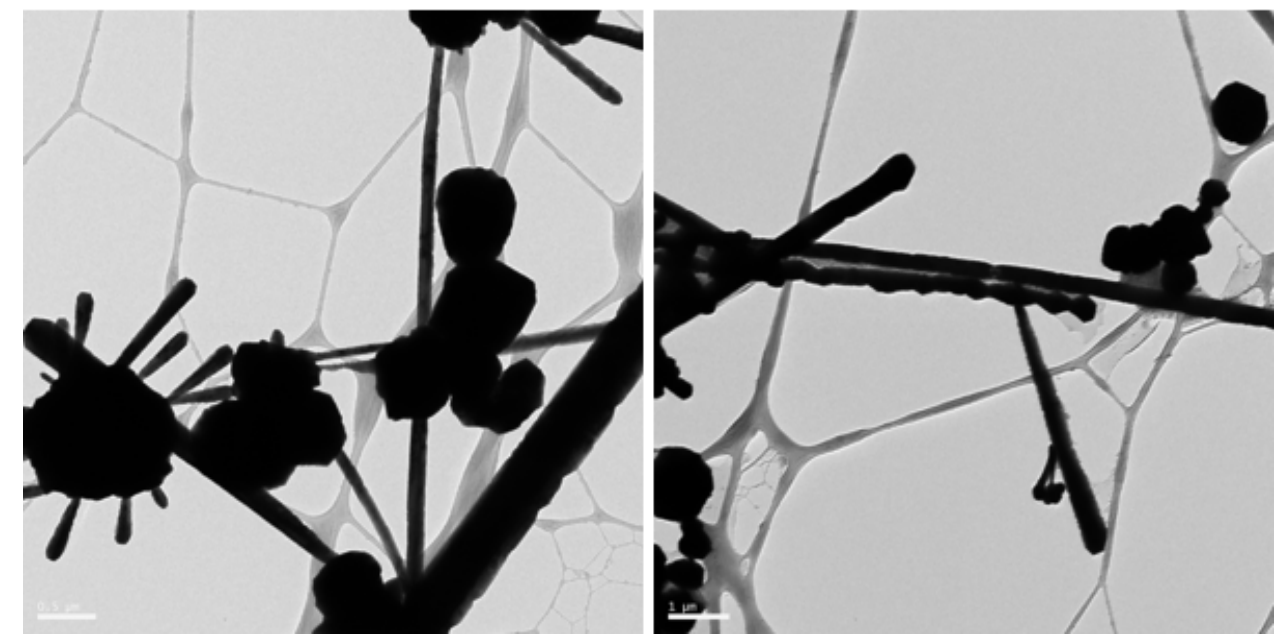

Figure 2.18: TEM images of copper nanowires with $12 \mathrm{M}$ of $\mathrm{NaOH}$

\section{The Effect of Concentration of Copper Precursor}

In order to determine the effect of concentration of copper precursor, copper nanowires are synthesized and compared yield and dimensions with the optimum copper nanowires. The concentration of $\mathrm{NaOH}, \mathrm{EDA}$, and $\mathrm{N}_{2} \mathrm{H}_{4}$ are $\mathrm{S} 4, \mathrm{E} 3,15 \mu \mathrm{l}$ of $\mathrm{N} 2$, respectively, and the reaction temperature is kept at $70{ }^{\circ} \mathrm{C}$ during the reaction time for 2 hours. This condition is the same except the concentration of $\mathrm{CuCl}_{2}$ as optimum copper nanowires, which are shown in Figure 2.16. The copper solution is employed with C2 condition.

As shown in Figure 2.19, copper nanowires indicate the length of longer than $6 \mu \mathrm{m}$ and the diameter of $100-240 \mathrm{~nm}$, which are thicker and shorter dimensions compared with Figure 2.16. In addition, the yield of copper nanowires is significantly decreased and the aggregation of copper seeds undescribed in Figure 2.16 is created. 


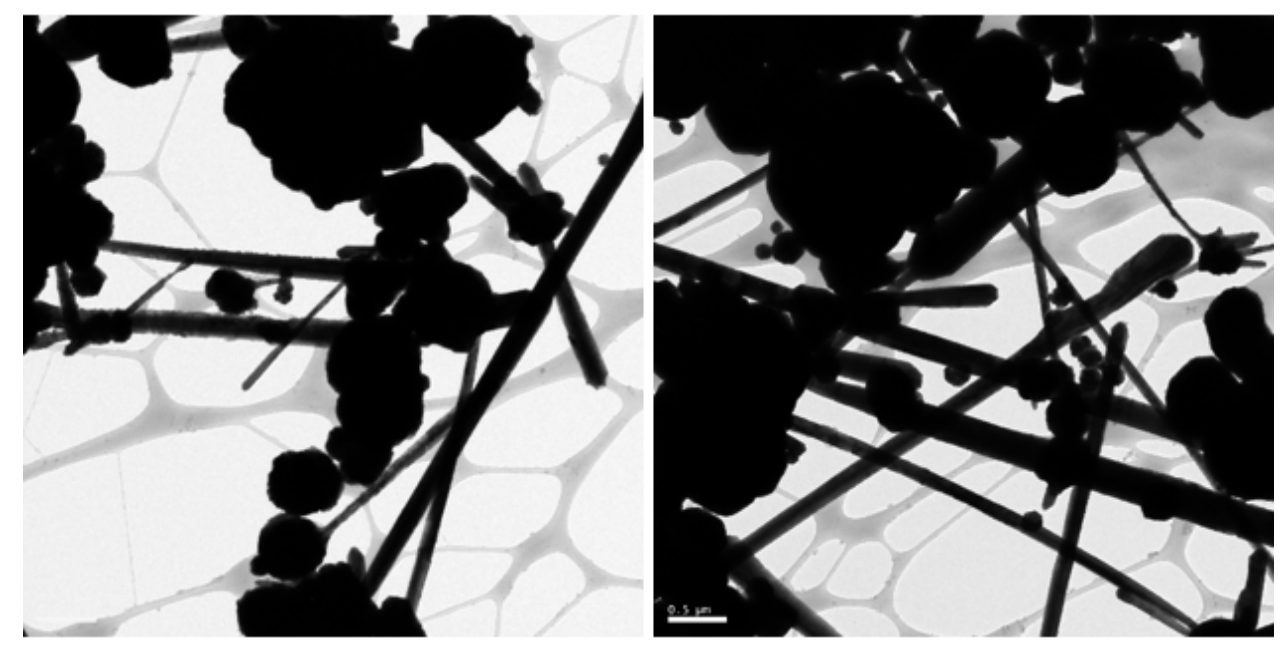

Figure 2.19: TEM images of copper nanowires with $37.2 \mathrm{mM}$ of copper precursor 


\subsection{Discussion}

High yield of copper nanowires is obtained under $15 \mu \mathrm{l}$ of diluted $\mathrm{N}_{2} \mathrm{H}_{4}$. However copper nanoparticles instead of copper nanowires are observed under overused diluted $\mathrm{N}_{2} H_{4}$. As the addition amount of diluted $\mathrm{N}_{2} H_{4}$ increases, the diameter of copper nanowires tends to become thicker. The overused diluted $\mathrm{N}_{2} H_{4}$ likely causes an unbalance in the process of growing copper nanowires from copper nanoparticles. This is because $\mathrm{N}_{2} H_{4}$ as strong reducing agent has sensitive effect to grow copper nanowires. Therefore, growing process might not be completely carried out and copper nanoparticles are dominated.

The surface of copper nanowires is not improved with increasing temperature from $40{ }^{\circ} \mathrm{C}$ to $60{ }^{\circ} \mathrm{C}$. However, the smooth surface is observed at $70{ }^{\circ} \mathrm{C}$. Broken damage of copper nanowires are observed at $80{ }^{\circ} \mathrm{C}$. At $90{ }^{\circ} \mathrm{C}$, not only copper nanowires and also copper nanoparticles are oxidized due to high temperature. As the reaction temperature increases, the diameter of copper nanowires tends not to become thinner or thicker continuously. Based on the phenomena of aggregation of copper seeds at $40{ }^{\circ} \mathrm{C}$ and $50{ }^{\circ} \mathrm{C}$, the role of EDA may be affected by the reaction temperature. Therefore, in order for EDA to perform actively and to protect the surfaces of copper seeds, the reaction temperature of at least $60{ }^{\circ} \mathrm{C}$, at which the aggregation of copper seeds is not observed, is likely required. The surface of copper nanowires is steadily improved by increasing reaction temperature from $40{ }^{\circ} \mathrm{C}$ to $70{ }^{\circ} \mathrm{C}$. This is because 
EDA is likely actively performed at $70{ }^{\circ} \mathrm{C}$ to offer sufficient surface energy to copper seeds. In addition, the relatively high temperature probably helps to produce copper seeds within a short period of time. However, at reaction temperature over $70{ }^{\circ} \mathrm{C}$, water in water-bath and copper nanowires solutions begin to evaporate. Especially, at $90^{\circ} \mathrm{C}$, their evaporation is accelerated. Due to this risk factor, $70{ }^{\circ} \mathrm{C}$ can be determined as reasonable temperature for synthesis of copper nanowires.

While copper seeds, which are not grown up to copper nanowire, and tapered copper nanowires are observed under $15 \mu \mathrm{l}$ of EDA, tapered copper nanowires are dominantly revealed under $50 \mu \mathrm{l}$ of EDA. Irregular surface of copper nanowires is obtained under $60 \mu \mathrm{l}$ of EDA even though the dimensions are improved. The tapered copper nanowires can be resulted from unstably protected copper seeds by EDA. This could lead to thicker diameter and short length of copper nanowires. Interestingly, the dimensions of copper nanowires are not proportional to the amount of EDA. As the amount of EDA increases or decreases, copper nanowires may be not indicated a certain dimensional change while distributing randomly. In addition, the addition any amount of EDA is not likely guaranteed the formation of copper nanowires completely, however, EDA may control the dimension of copper nanowires when comparing with the research of Tan and Balela [2017] in the absence of EDA. The overused amount of EDA can surround erratically copper seeds, which probably result in irregular the surface of copper nanowires including copper nanoparticles as shown in Figure 2.13. This surface can be induced the deficiency of copper nanowires, which likely 
reduces the electrical conductivity. Therefore, the optimal addition amount of EDA is essential to protect copper seeds and prevent the formation of tapered copper nanowires.

As the concentration of $\mathrm{NaOH}$ steadily increases from $5 \mathrm{M}$ to $9 \mathrm{M}$, the dimensions of copper nanowires are improved noticeably. In addition, high-quality of copper nanowires is obtained with $9 \mathrm{M}$ of $\mathrm{NaOH}$. However, the excessive concentration over $9 \mathrm{M}$ begins to cause incomplete growth of copper nanowires. It can be assumed that high concentration of $\mathrm{NaOH}$ could not be completely dissolved, and remaining $\mathrm{NaOH}$ may prevent copper seeds from being covered by EDA. The condition of 5 $\mathrm{M}$ and $7 \mathrm{M}$ of $\mathrm{NaOH}$ is likely required increased amount of EDA to improve the aggregation of copper seeds. It means that low concentration of $\mathrm{NaOH}$ probably interplays with high amount of EDA. In addition, the quality of copper nanowires is greatly improved with only change of concentration of $\mathrm{NaOH}$ as compared Figure 2.12 and 2.16. $\mathrm{NaOH}$ is required to excess amount than copper precursor because it is consistently consumed during reaction. However, its concentration and the amount of EDA may be controlled at the same time to obtain regularity copper nanowires.

Only the concentration of copper precursor is increased from the condition where high-quality of copper nanowires is obtained. As a result, undesirable copper nanowires including thicker diameter and the aggregation are obtained. The increased concentration of copper precursor likely causes to form larger size of copper seeds, which induce thicker diameter of copper nanowire, and to form the aggregation of copper 
seeds. This is because EDA cannot cover the copper seeds formed from increased concentration of copper precursor. Therefore, these copper seeds probably may begin to agglomerate each other and to form short length of copper nanowires. In order to synthesize well-aligned copper nanowires under increased concentration of copper precursor, the amount of EDA, which can protect copper seeds, may also need to be increased. 


\section{Chapter 3}

\section{Fabrication of Core-Shell Nanowire}

\subsection{Materials}

In order to fabricate core-shell $(\mathrm{Cu}-\mathrm{Ag})$ nanowire, silver nitrate $\left(\mathrm{AgNO}_{3}\right)$ is utilized as shell material to coat on the surface of pre-synthesized copper nanowires. Deionized water (DI $\mathrm{H}_{2} \mathrm{O}$ ) is employed as solvent to dissolve silver salt. In addition, organic compound $\mathrm{A}$ is used as copper surfactant and silver reducing agent.

\subsection{Experimental Procedure}

Core-shell (Cu-Ag) nanowires are prepared by a new facile method using organic compound A. As shown in Figure 3.1, this process is conducted by addition of organic compound A and silver solution at room temperature without electrode and heating. In a typical process, $0.3 \mathrm{mg}$ of $\mathrm{AgNO}_{3}$ is dissolved in $2 \mathrm{ml}$ of $\mathrm{DI}_{2} \mathrm{O}$ and $300 \mu \mathrm{l}$ of silver solution is dropped into well-dispersed copper nanowires including $1 \mathrm{wt} \%$ of organic compound A solution. After adding silver solution, the solution color is changed from reddish brown to dark grey, which means that coating process is started 


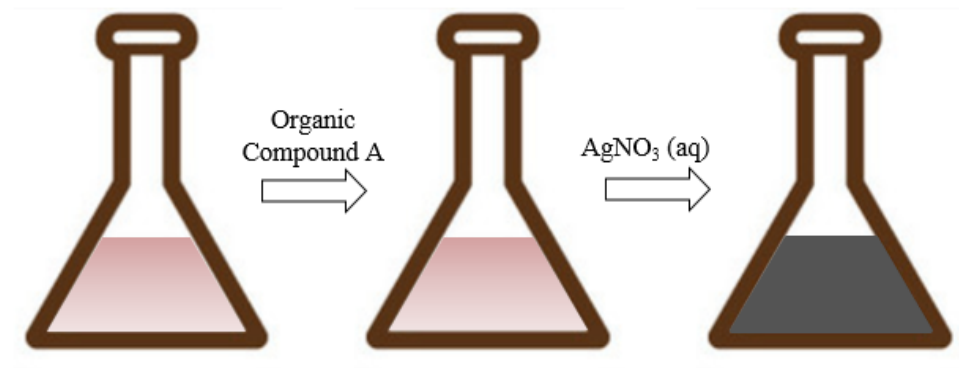

Figure 3.1: Fabrication process of $\mathrm{Cu}-\mathrm{Ag}$ nanowires

Table 3.1: Experimental condition of chemicals

\begin{tabular}{|c|c|c|c|c|}
\hline $\begin{array}{c}\text { Organic Compound } \mathrm{A} \\
(\mathrm{wt} \%)\end{array}$ & $\mathrm{AgNO}_{3}(\mathrm{mg})$ & $\mathrm{DI} \mathrm{H} \mathrm{H}_{2} \mathrm{O}(\mathrm{ml})$ & Molarity $(\mathrm{mM})$ & Vol. $(\mu \mathrm{l})$ \\
\hline 1 & 0.3 & 2 & 0.88 & 300 \\
\hline
\end{tabular}

in the solution. The final solution is stirred with an ultrasonication for 10 min. Table 3.1 shows the summary of chemicals condition for coating process.

\subsection{Results}

The core-shell $(\mathrm{Cu}-\mathrm{Ag})$ structure nanowires are prepared by adding $300 \mu \mathrm{l}$ of silver solution with a new facile method. In this experiment, silver coating is induced because of oxidation-reduction reaction between copper and silver according to the following chemical equation (3.1):

$$
\begin{array}{ll}
C u \rightarrow C u^{2+}+2 e^{-} & : E^{0}=-0.3419 V \\
A g^{+}+e^{-} \rightarrow A g & : E^{0}=+0.7996 V \\
C u+2 A g^{+} \rightarrow C u^{2+}+2 A g \downarrow & : \Delta E^{0}=+0.4577 V
\end{array}
$$


The reaction between copper and silver occurs spontaneously because the difference of redox potential $\left(\Delta E^{0}\right)$ is positive with $+0.4577 \mathrm{~V}$ as shown in chemical equation (3.1). Silver has higher reduction potential than copper, therefore, silver ions can be reduced to silver atom (Wei et al. [2015];Zhao et al. [2015]).

Figure 3.2 indicates SEM images of copper nanowires after coating with silver. $\mathrm{Cu}-\mathrm{Ag}$ nanowires display the length of longer than $15 \mu \mathrm{m}$. Compared with Figure 2.17, which is before coating with silver, the surface of copper nanowires in Figure 3.2 is revealed slightly rough because of the formation of silver shell. The surface of $\mathrm{Cu}-\mathrm{Ag}$ nanowires and morphology are investigated by the TEM image and silver shell is showed well-covered onto the surface of copper nanowires as shown in Figure 3.3. The diameter of copper core nanowires and thickness of silver shell are likely difficult to accurately measure by TEM image because the precise boundaries are not indicated between them. However, the diameter of copper core nanowires and thickness of silver shell are displayed at value close to $90 \mathrm{~nm}$ and $12 \mathrm{~nm}$, respectively, from Figure 3.3. 

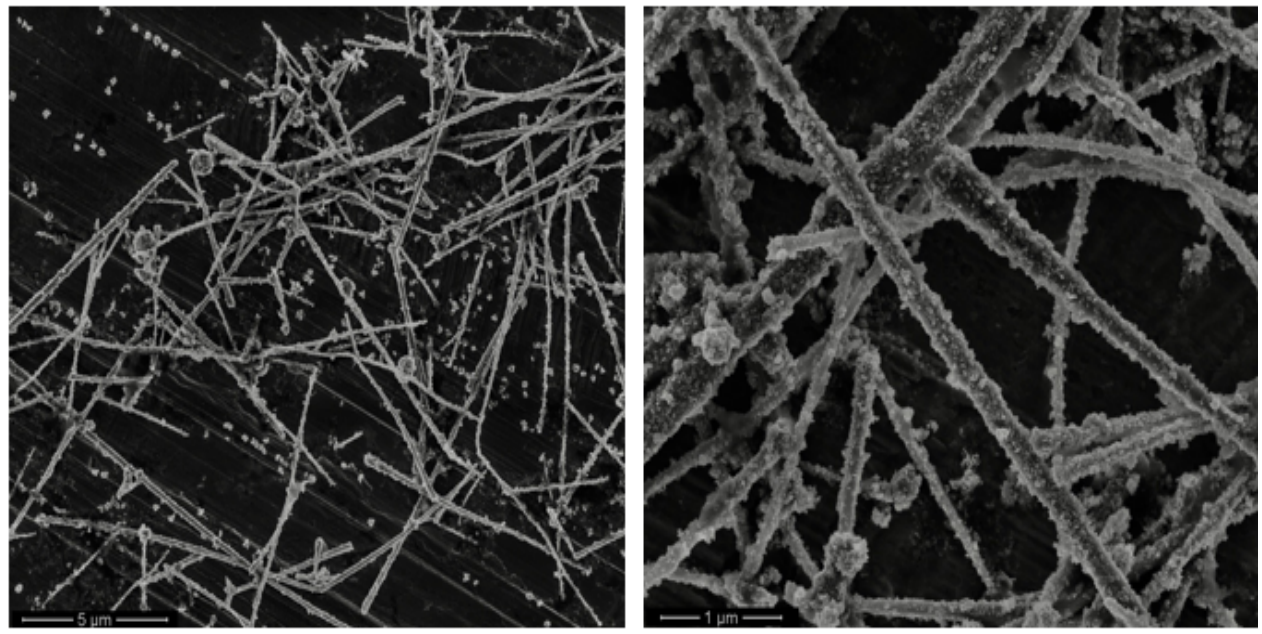

Figure 3.2: $\mathrm{SEM}$ images of $\mathrm{Cu}-\mathrm{Ag}$ nanowires

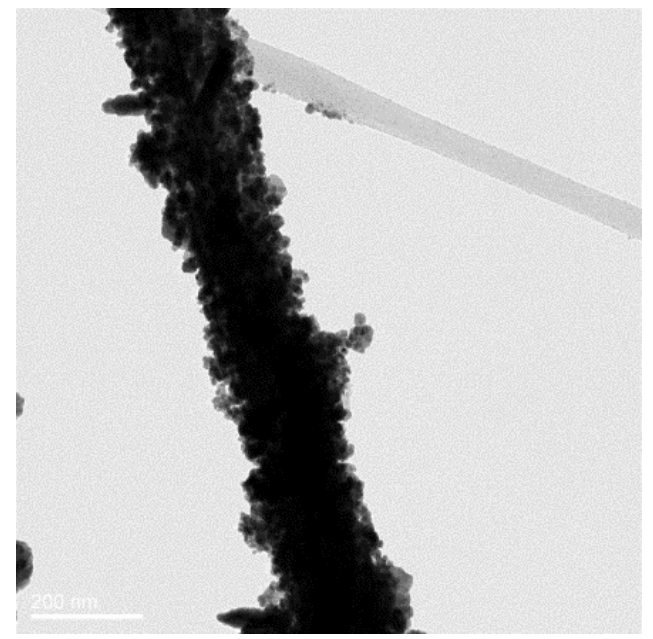

Figure 3.3: TEM image of $\mathrm{Cu}-\mathrm{Ag}$ nanowires 


\subsection{Discussion}

$\mathrm{Cu}-\mathrm{Ag}$ nanowires are successfully fabricated through a new facile method using organic compound A. The oxidation resistance, which can determine the electrical property of $\mathrm{Cu}-\mathrm{Ag}$ nanowires, may be different depending on silver shell thickness. At least the shell thickness of $5 \mathrm{~nm}$ is necessary for preventing the oxidation, however, the thickness close to $15 \mathrm{~nm}$ is superior oxidation resistance compared with that of 5 nm (Stewart et al. [2015]). In this experiment, fabricated $\mathrm{Cu}-\mathrm{Ag}$ nanowires, may not only prevent the oxidation of copper nanowire due to the thickness silver shell of 12 $\mathrm{nm}$, which are the value close to $15 \mathrm{~nm}$, but may also maintain superior conductivity competed with silver. 


\section{Chapter 4}

\section{Conclusions}

In summary, this study was to optimize the synthesis of copper nanowire to improve the quality of copper nanowires using the solution-based method. The copper nanowires were characterized by SEM and TEM. In order to determine and evaluate the quality of copper nanowires, the effects of concentrations of $\mathrm{N}_{2} \mathrm{H}_{4}, \mathrm{EDA}, \mathrm{NaOH}$, and copper precursor and various synthesis temperatures were studied. In addition, the fabrication of core-shell $(\mathrm{Cu}-\mathrm{Ag})$ nanowires, which were covered with silver on the surface of copper nanowire, was achieved by using organic compound A. The $\mathrm{Cu}-\mathrm{Ag}$ nanowires were characterized by SEM and TEM. Consequently, this study proposed the optimization of synthesis of copper nanowires and a new facile method for fabricating of $\mathrm{Cu}-\mathrm{Ag}$ nanowires.

The effect of concentrations of $\mathrm{N}_{2} H_{4}$ as reducing agent is conducted. The diameter

of copper nanowires tended to become thicker along increasing the amount of diluted $\mathrm{N}_{2} H_{4}$. The excessive addition amount of diluted $\mathrm{N}_{2} H_{4}$ can be caused an unbalance in the synthesis process. 
In terms of the effect of various synthesis temperatures, the relatively low temperature such as $40{ }^{\circ} \mathrm{C}$ and $50{ }^{\circ} \mathrm{C}$, the aggregation of copper seeds was dominated. Thus, the reaction temperature of least $60^{\circ} \mathrm{C}$, at which the aggregation of copper seeds was not observed, were suitable to synthesize copper nanowires. In addition, EDA were actively performed at $70{ }^{\circ} \mathrm{C}$ showing smooth surface of copper nanowire. However, the temperature over $70{ }^{\circ} \mathrm{C}$ has potential risk of water and solution evaporation, and oxidation of copper nanowires during reaction time.

The tapered copper nanowires were resulted from unstable protected copper seeds by EDA. As the amount of EDA increased or decreased, copper nanowires do not show proportionally dimensional change. The addition of EDA was not guaranteed the formation of copper nanowires completely, however, the amount of EDA can have potential control the dimension of copper nanowires. However, overused EDA could surround erratically copper seeds, which resulted in irregular the surface of copper nanowires including copper nanoparticles. Therefore, the optimum amount of EDA was essential to protect copper seeds and prevent the formation of tapered copper nanowires.

The high-quality of copper nanowires, which displayed the length of longer than $18 \mu \mathrm{m}$ and the diameter of $25-45 \mathrm{~nm}$ with high yield, were obtained under $9 \mathrm{M}$ of $\mathrm{NaOH}$ condition. The condition of $5 \mathrm{M}$ and $7 \mathrm{M}$ of $\mathrm{NaOH}$ was likely required the increased amount of EDA to prevent the aggregation of copper seeds. The excessive concentration over $9 \mathrm{M}$ of $\mathrm{NaOH}$ was likely to prevent copper seeds from being cov- 
ered by EDA. Therefore, the concentration of $\mathrm{NaOH}$ and EDA was required to be controlled at the same time to obtain regularity copper nanowires.

In the case of the high concentration of copper precursor than $17.1 \mathrm{mM}$ was added in the solution containing of $50 \mu \mathrm{l}$ of EDA, the formation of large size of copper seeds that induce thicker diameter of copper nanowires was caused and the aggregation of copper seeds was formed due to insufficient of EDA. Therefore, increased amount of EDA than $50 \mu \mathrm{l}$ might be required to protect copper seeds properly to synthesize well-aligned copper nanowires under the high concentration of copper precursor thatn $17.1 \mathrm{mM}$.

$\mathrm{Cu}-\mathrm{Ag}$ nanowires were successfully fabricated by a new facile method using organic compound A. The thickness of silver shell was measured the value close to $12 \mathrm{~nm}$. This thickness is likely suitable to prevent copper nanowires from being oxidized compared with the results discussed by Stewart et al. [2015] that at least 5nm thickness of silver shell enables to protect copper nanowire from oxidation and increasing thickness of silver shell is more effective.

As a result, the synthesis of copper nanowires for high-quality were optimized by $9 \mathrm{M}$ of $\mathrm{NaOH}, 50 \mu \mathrm{l}$ of EDA, $17.1 \mathrm{mM}$ of $\mathrm{CuCl}_{2}$, and $5.7 \mathrm{mM}$ of $\mathrm{N}_{2} H_{4}$. In addition, a new facile method using organic compound A for fabrication of core-shell $(\mathrm{Cu}-\mathrm{Ag})$ nanowires was developed. 


\section{Bibliography}

P. C. Hsu, S. Wang, H. Wu, V. K. Narasimhan, D. Kong, H. R. Lee, and Y. Cui. Performance enhancement of metal nanowire transparent conducting electrodes by mesoscale metal wires. Nature communications, 36:2522, 2013.

L. Hu, H. Wu, and Y. Cui. Metal nanogrids, nanowires, and nanofibers for transparent electrodes. MRS bulletin, 36:760-765, 2011.

P. Lee, J. Lee, H. Lee, J. Yeo, S. Hong, K. H. Nam, and S. H. Ko. Highly stretchable and highly conductive metal electrode by very long metal nanowire percolation network. Advanced materials, 24:3362-3332, 2012.

A. R. Rathmell, S. M. Bergin, Y. L. Hua, Z. Y. Li, and B. J. Wiley. The growth mechanism of copper nanowires and their properties in flexible, transparent conducting films. Advanced materials, 22:3558-3563, 2010.

B. W. Nuryadin, M. Purwanto, H. Aliah, Y. S. Perkasa, and E. C. S. Mahen. Effect of synthesis temperature on the morphology and electrical properties of solution 
grown copper nanowires (cunws). In AIP Conference Proceedings, 1078:070009, 2016.

D. Mardiansyah, K. Triyana, and H H. Harsojo. Effect of precursor molar ratio on the yield of cu nanowires synthesized using aqueous solution method. International Journal on Advanced Science, Engineering and Information Technology, 6:447-450, 2013.

M. R. Tan and M. D. L. Balela. Electrochemical investigation of the growth of copper nanowires in the presence of ethylenediamine through mixed potential. Journal of The Electrochemical Society, 164:D386-D393, 2017.

S. Ye, A. R. Rathmell, I. E. Stewart, Y. C. Ha, A. R. Wilson, Z. Chen, and B. J. Wiley. A rapid synthesis of high aspect ratio copper nanowires for high performance transparent conducting films. Chemical Communications, 50:2562-2564, 2014a.

Z. Niu, F. Cui, Y. Yu, N. Becknell, Y. Sun, G. Khanarian, and P. Yang. Ultrathin epitaxial cu@ au core-shell nanowires for stable transparent conductors. Journal of the American Chemical Society, 139:7348-7354, 2017.

Z. Chen, S. Ye, A. R. Wilson, Y. C. Ha, and B. J. Wiley. Optically transparent hydrogen evolution catalysts made from networks of copper-platinum core-shell nanowires. Energy and Environmental Science, 7:1461-1467, 2014. 
A. R. Rathmell, M. Nguyen, M. Chi, and B. J. Wiley. Synthesis of oxidation-resistant cupronickel nanowires for transparent conducting nanowire networks. Nano letters, 12:3193-3199, 2012.

J. Zhao, D. Zhang, and X. Zhang. Preparation and characterization of copper/silver bimetallic nanowires with core-shell structure. Surface and Interface Analysis, 47: $529-534,2015$.

Y. Zhang, J. Guo, D. Xu, Y. Sun, and F. Yan. Synthesis of ultrathin semicircle-shaped copper nanowires in ethanol solution for low haze flexible transparent conductors. Nano Research, 11):3899-3910, 2018a.

H. Guo, N. Lin, Y. Chen, Z. Wang, Q. Xie, T. Zheng, and D. L. Peng. Copper nanowires as fully transparent conductive electrodes. Scientific reports, 3:2323, 2013

Y. Wang, P. Liu, B. Zeng, L. Liu, and J. Yang. Facile synthesis of ultralong and thin copper nanowires and its application to high-performance flexible transparent conductive electrodes. Nanoscale research letters, 13:78, 2018.

C. Hwang, J. An, B. D. Choi, K. Kim, S. W. Jung, K. Baeg, and Ji. Hong. Controlled aqueous synthesis of ultra-long copper nanowires for stretchable transparent conducting electrode. Journal of Materials Chemistry C, 4:1441-1447, 2016. 
S. Naghdi, K. Rhee, D. Hui, and S. Park. A review of conductive metal nanomaterials as conductive, transparent, and flexible coatings, thin films, and conductive fillers: Different deposition methods and applications. Coating, 8:278, 2018.

J. Koo, S. Kwon, N. R. Kim, K. Shin, and H. M. Lee. Ethylenediamine-enhanced oxidation resistivity of a copper surface during water-based copper nanowire synthesis. The Journal of Physical Chemistry C, 120:14293-14286, 2016.

D. Zhang, R. Wang, M. Wen, D. Weng, X. Cui, J. Sun, and Y. Lu. Synthesis of ultralong copper nanowires for high-performance transparent electrodes. Journal of the American Chemical Society, 120:3334-3340, 2012.

A. R. Rathmell and B. J. Wiley. The synthesis and coating of long, thin copper nanowires to make flexible, transparent conducting films on plastic substrates. Advanced Materials, 23:4798-4803, 2011.

A. Vaseashta and D. Dimova Malinovska. Nanostructured and nanoscale devices, sensors and detectors. Science and Technology of Advanced Materials, 6:312-318, 2005.

V. Nam and D. Lee. Copper nanowires as conductive ink for low-cost draw-on electronics. Nanomaterials, 2016.

N. N. Jason, W. Shen, and W. Cheng. Copper nanowires as conductive ink for low 
cost draw on electronics. ACS applied materials and interfaces, 7:16760-16766, 2015.

D. R. Kumar, K. Woo, and J. Moon. Promising wet chemical strategies to synthesize cu nanowires for emerging electronic applications. Nanoscale, 7:17195-17210, 2015.

R. Wang and H. Ruan. Synthesis of copper nanowires and its application to flexible transparent electrode. Journal of Alloys and Compounds, 656:936-943, 2016.

S. Zhao, F. Han, J. Li, X. Meng, W. Huang, D. Cao, and C. P. Wong. Advancements in copper nanowires: Synthesis, purification, assemblies, surface modification, and applications. Small, -:-, 2016.

H. Ruan, R. Wang, Y. Luo, H. Liu, T. Han, and L. Yang. Study on synthesis and growth mechanism of copper nanowires via a facile oleylamine mediated process. Journal of Materials Science: Materials in Electronics, 27:9405-9409, 2016.

S. Ding, Y. Tian, J. Jiu, and K. Suganuma. Highly conductive and transparent copper nanowire electrodes on surface coated flexible and heat sensitive substrates. $R S C$ Advances, 8:2109-2115, 2018.

T. H. Duong and H. C. Kim. A high productivity and speedy synthesis process for copper nanowires via an ethylenediamine mediated method. International Nano Letters, 7:165-169, 2017. 
S. Ye, I. E. Stewart, Z. Chen, B. Li, A. R. Rathmel, and B. J. Wiley. How copper nanowires grow and how to control their properties. Accounts of chemical research, 49:442-451, 2016.

N. H. Tran, T. H. Duong, and H. C. Kim. A fast fabrication of copper nanowire transparent conductive electrodes by using pulsed laser irradiation. Scientific reports, 7: 15093, 2017.

Y. Wei, S. Chen, Y. Lin, Z. Yang, and L. Liu. Cu ag core shell nanowires for electronic skin with a petal molded microstructure. Journal of Materials Chemistry C, 3: 9594-6902, 2015.

D. Mardiansyah, T. Badloe, K. Triyana, M. Q. Mehmood, N. Raeis Hosseini, Y. Lee, and J. Rho. Effect of temperature on the oxidation of cu nanowires and development of an easy to produce, oxidation-resistant transparent conducting electrode using a pedot: Pss coating. Scientific reports, 8:10639, 2018.

X. Luo, G. A. Gelves, U. Sundararaj, and J. L. Luo. Silver coated copper nanowires with improved anti oxidation property as conductive fillers in low density polyethylene. The Canadian Journal of Chemical Engineering, 91:630-637, 2013.

American Element. 2019. URL https://www. americanelements.com.

Y. Zhang, J. Guo, D. Xu, Y. Sun, and F. Yan. Synthesis of ultralong copper nanowires 
for high-performance flexible transparent conductive electrodes: The effects of polyhydric alcohols. Langmuir, 34:3884-3893, 2018b.

H. C. Chu, Y. C. Chang, Y. Lin, S. H. Chang, W. C. Chang, G. A. Li, and H. Y. Tuan. Spray-deposited large-area copper nanowire transparent conductive electrodes and their uses for touch screen applications. ACS applied materials and interfaces, 8: 13009-13017, 2016.

S. Bhanushali, P. Ghosh, A. Ganesh, and W. Cheng. 1d copper nanostructures: progress, challenges and opportunities. Small, 11:1232-1252, 2015.

H. Choi and S. H. Park. Seedless growth of free standing copper nanowires by chemical vapor deposition. Journal of the American Chemical Society, 126:6248-6249, 2004.

C. Kim, W. Gu, M. Briceno, I. M. Robertson, H. Choi, and K. Kim. Copper nanowires with a five twinned structure grown by chemical vapor deposition. Advanced $M a$ terials, 20:1859-1863, 2008.

D. Haase, S. Hampel, A. Leonhardt, J. Thomas, N. Mattern, and B. Buchner. Facile one step synthesis of carbon wrapped copper nanowires by thermal decomposition of copper (ii) acetylacetonate. Surface and Coatings Technology, 201:9184-9188, 2007.

R. Inguanta, S. Piazza, and C. Sunseri. Influence of the electrical parameters on the 
fabrication of copper nanowires into anodic alumina templates. Applied Surface Science, 255:8816-8823, 2009.

G. A. Gelves, Z. T. Murakami, M. J. Krantz, and J. A. Haber. Multigram synthesis of copper nanowires using ac electrodeposition into porous aluminum oxide templates. Journal of Materials Chemistry, 16:3075-3083, 2006.

J. Pate, F. Zamora, S. M. Watson, N. G. Wright, B. R. Horrocks, and A A. Houlton. Solution based dna templating of sub $10 \mathrm{~nm}$ conductive copper nanowires. Journal of Materials Chemistry C, 2:9265-9273, 2014.

C. F. Monson and A. T. Woolley. Dna templated construction of copper nanowires. Nano letters, 3:359-363, 2003.

Y. Chang, M. L. Lye, and H. C. Zeng. Large scale synthesis of high quality ultralong copper nanowires. Langmuir, 21:3746-3748, 2005.

M. J. Kim, P. F. Flowers, I. E. Stewart, S. Ye, S. Baek, J. J. Kim, and B. J. Wiley. Ethylenediamine promotes cu nanowire growth by inhibiting oxidation of cu (111). Journal of the American Chemical Society, 139:277-284, 2016.

S. Ye, A. R. Rathmell, Z. Chen, I. E. Stewart, and B. J. Wiley. Metal nanowire networks: the next generation of transparent conductors. Advanced materials, 26: 6670-6678, 2014b. 
H. Harsojo, L. A. Puspita, D. Mardiansyah, R. Roto, and K. Triyana. The roles of hydrazine and ethylene diamine in wet synthesis of cu nano wire. Indonesian Journal of Chemistry, 17:43-48, 2017.

A. P. Periasamy, J. Liu, H. M. Lin, and H. T. Chang. Synthesis of copper nanowire decorated reduced graphene oxide for electro oxidation of methanol. Journal of Materials Chemistry A, 19:5979-5981, 2013.

J. L. Cuya Huaman, I. Urushizaki, and B. Jeyadevan. Large scale cu nanowire synthesis by pvp ethylene glycol route. Journal of Nanomaterials, 2018.

S. Li, Y. Chen, L. Huang, and D. Pan. Large-scale synthesis of well-dispersed copper nanowires in an electric pressure cooker and their application in transparent and conductive networks. Inorganic chemistry, 53:4440-4444, 2014.

M. Jin, G. He, H. Zhang, J. Zeng, Z. Xie, and Y. Xia. Shape controlled synthesis of copper nanocrystals in an aqueous solution with glucose as a reducing agent and hexadecylamine as a capping agent. Angewandte Chemie International Edition, 50: 10560-10564, 2011.

F. Cui, Y. Yu, L. Dou, J. Sun, Q. Yang, C. Schildknecht, and P. Yang. Synthesis of ultrathin copper nanowires using tris (trimethylsilyl) silane for high performance and low haze transparent conductors. Nano letters, 15:7610-7615, 2015. 
Z. Tang, A. Shahzad, W. S. Kim, and T. Yu. Cost effective aqueous phase synthesis of long copper nanowires. RSC Advances, 5:83880-83884, 2015.

J. Mock, M. Bobinger, C. Bogner, P. Lugli, and M. Becherer. Aqueous synthesis, degradation, and encapsulation of copper nanowires for transparent electrodes. Nanomaterials, 8:797, 2018.

Z. Yin, C. Lee, S. Cho, J. Yoo, Y. Piao, and Y. S. Kim. Facile synthesis of oxidationresistant copper nanowires toward solution-processable, flexible, foldable, and freestanding electrodess. Small, 10:5047-5052, 2014.

X. Zhang and Z. Cui. Synthesis of cu nanowires via solventhermal reduction in reverse microemulsion system. In Journal of Physics: Conference Series, 152:012022, 2009.

A. Rathmell. Metal nanowires: Synthesis, processing, and structure-property relationships in the context of flexible transparent conducting films. Doctoral Dissertation, 2013.

T. Y. Lin, Y. L. Chen, C. F. Chang, G. M. Huang, C. W. Huang, C. Y. Hsieh, and L. J. Chen. In situ investigation of defect free copper nanowire growth. Nano letters, 18:778-784, 2018.

C. Xu, Y. Wang, H. Chen, R. Zhou, and Y. Liu. Large scale synthesis of ultralong copper nanowires via a facile ethylenediamine mediated process. Journal of Materials Science: Materials in Electronics, 25:2344-2347, 2014. 
S. Ye, A. R. Rathmell, Y. C. Ha, A. R. Wilson, and B. J. Wiley. The role of cuprous oxide seeds in the one pot and seeded syntheses of copper nanowires. Small, 10: 1771-1778, 2014c.

X. Liu and Y. Zhou. Electrochemical synthesis and room temperature oxidation behavior of cu nanowires. Journal of materials research, 20:2371-2378, 2005.

L. Xu, Y. Yang, Z. W. Hu, and S. H. Yu. Comparison study on the stability of copper nanowires and their oxidation kinetics in gas and liquid. ACS nano, 10:3823-3834, 2016

Z. Chen, A. R. Rathmell, S. Ye, A. R. Wilson, and B. J. Wiley. Optically transparent water oxidation catalysts based on copper nanowires. Angewandte Chemie International Edition, 52:13708-13711, 2013.

C. Lee, N. R. Kim, J. Koo, Y. J. Lee, and H. M. Lee. Cu-ag core-shell nanoparticles with enhanced oxidation stability for printed electronics. Nanotechnology, 26: 455601, 2015.

X. Xia, Y. Wang abd A. Ruditskiy, and Y. Xia. 25th anniversary article: Galvanic replacement: a simple and versatile route to hollow nanostructures with tunable and well-controlled properties. Advanced Materials, 25:6313-6333, 2013.

Z. Jiang, Y. Tian, S. Ding, J. Wen, and C. Wang. Facile synthesis of cu-ag hybrid 
nanowires with strong surface-enhanced raman scattering sensitivity. Cryst Eng Comm, 18:1200-1206, 2016.

I. E. Stewart, S. Ye, Z. Chen, P. F. Flowers, and B. J. Wiley. Synthesis of cu-ag,

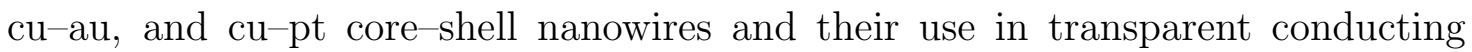
films. chemistry of Materials, 27:7788-7794, 2015.

M. A. Cruz, S. Ye, M. J. Kim, C. Reyes, F. Yang abd P. F. Flowers, and B. J. Wiley. Multigram synthesis of cu-ag core-shell nanowires enables the production of a highly conductive polymer filament for $3 \mathrm{~d}$ printing electronics. Particle and Particle Systems Characterization, 35:1700385, 2018.

X. Wen, Y. Xie, C. L. Choi, K. C. Wan, X. Y. Li, and S. Yang. Copper based nanowire materials: templated syntheses, characterizations, and applications. Langmuir, 21: $4729-4739,2005$. 